\title{
Global Cities and Socioeconomic Inequality: A Pathways Inquiry
}

\author{
By \\ Herman L. Boschken \\ Professor Emeritus \\ San Jose State University \\ Email: herman.boschken@sjsu.edu
}

\begin{abstract}
Inequality in metropolitan areas is part of a paradoxical triangle of competing motives over resources allocation. Chief among inequality/equity rivals is the penchant for urban economic development, but in recent decades, ecological sustainability has also become increasingly important in this triangle. To understand inequality in global cities in such a context, one must recognize the intensity of economic development motives for those particular metropolitan areas seeking to maintain worldwide centrality, connectivity and command over the forces of globalization. As a comparative analysis of 53 large U.S. metropolitan areas, this paper examines the apparatus of a global city in response to globalization, particularly since such metropolitan areas produce higher socioeconomic inequality than other places. Through a causal path analysis, it empirically uncovers essential components of the paradoxical triangle in the ongoing struggle of global cities to sustain their world-city status. In so doing, the evidence suggests heightened inequality is a function of (a) the global city's use of certain "cornerstone" resources to sustain global advantage, and (b) its resultant polarized employment structure and commensurate skewed social stratification.
\end{abstract}

KEY WORDS: globalization, global city, economic development, income inequality, polarization, technology, innovation, sustainability, employment structure, immigration, metropolitan, urban policy

ACKNOWLEDGEMENTS: Special gratitude is expressed to Dan Silver (University of Toronto), Saskia Sassen (Columbia University) and Richard Florida (University of Toronto) for their insightful critiques and revision suggestions of an earlier draft of this paper.

A paper presented at the 2020 Meeting of the American Political Science Association San Francisco, September 9 -13. Copyright 2020 by Herman L. Boschken 


\section{Global Cities and Socioeconomic Inequality: A Pathways Inquiry}

Research into inequality in urban America tends to be couched in a triangle of competing paradigms that juxtapose economic development, ecological sustainability, and socioeconomic equity - the "Three Es" (Saha and Paterson, 2008). Although mincing distinctions among the three paradigms is common, as seen in the literature on "sustainable economic development" (Burns, 2016; Brundtland, 1987; Parkin, Sommer and Uren, 2003; Lele, 1991), complex paradoxical dichotomies arising among them persist in practice. Often saddled with insoluble tensions among the Three Es, policymakers are left to deal with the attendant "wicked problems" and difficult tradeoffs (Rittel and Webber, 1973). Moreover, with respect to socioeconomic equity, tradeoffs involving zero-sum outcomes favoring economic development and/or sustainability appear to be the norm, causing large inequalities to persist in urban outcomes. Reflecting on such tradeoffs, Englehart and Norris, argue that despite major developmental and ecological progress, "a large share of the population in high-income countries has experienced declining real income, declining job security, and rising income inequality..." (2017, p. 447). Among high-income countries, the U.S. exhibits the highest level of economic inequality (Luxembourg Income Study, 2019). Further, Katz and Krueger point to evidence for the U.S., that indicates "intergenerational absolute income mobility has declined substantially" (2017, p. 1), leaving younger generations at continued risk of lives diminished in opportunity and achievement relative to those of their parents.

In both media coverage and academic research, such zero-sum outcomes are highly visible at both national and urban levels (e.g., Harrison, 2019; Krugman, 2018; Stiglitz, 2016). Furthermore, the precipitous 50-year rise in U.S. income inequality (e.g., Piketty, Saez and Zucman, 2016; Pew Research Center, 2015) suggests that the equity issue is at least coincidental 
with the rise of post-Cold War globalization. For example, worldwide integration of economic development activity, commencing in the 1970s, retrospectively takes on a whole new contextual dimension in the American experience that notably includes a significant rise in socioeconomic inequalities.

A plethora of agents are often identified as seminal aspects of this global integration, including "off shoring" of production, labor migrations, technological innovation involving both job replacement (e.g., robotics) and job augmentation (e.g., AI), worldwide supply-chain competition, declining union power, and highly-concentrated, technology-enabled corporate global "command and control" networks. But, is the corrosive role of globalization on inequality manifested principally as nationally-uniform impacts on unions and supply-chain effects on manufacturing? Or, might globalization's impacts also be uniquely operating through particular attributes of those metropolitan areas most integrally connected to globalization? If the latter, can we distinguish some of the causes and the severity of those inequality impacts as a function of a metropolitan area's "global-city" status?

Most often, these macro agents of globalization and their consequences for socioeconomic equity are examined with respect to the national scene or Federal policymaking, with less focus on their comparative consequences occurring at an urban level (see, for example, Harrison, 2019; Piketty, Saez and Zucman, 2016; Stiglitz, 2016; Inglehart, 2016; Alden, 2016). A few, however, argue that regional or metropolitan inequality is inextricably tied to nationallevel wealth disparities, thus concluding that differences in metropolitan inequality is a function of the national scene (see, for example, Manduca, 2019). Even with different takes on national relevance, minimizing the urban origins of inequality would seem to be a major oversight. 
Metropolitan areas are not uniform in their indigenous context or in the connectivity they have with globalization and the centrality they maintain in global economic networks. Moreover, metropolitan-level involvement with globalization is unlikely attributable in the same way to the aforementioned macro agents of globalization. What is likely left out of the equation are numerous mediating or intervening variables that make up the place-based employment capacities, resources and activities distinguishing one metropolitan area from another which are promulgated by their differential connectivity and centrality to globalization.

One might therefore expect urban outcomes of globalization, especially their indigenous development consequences on socioeconomic equity, to vary widely across metropolitan areas. Addressing this premise, the paper reports research which adopts a cross-sectional comparative urban focus examining the presence of inequality across a sample of 53 large metropolitan areas (MSAs) in the U.S. It does not involve analysis of temporal or longitudinal data, although the research may take up time-series analysis at a later time.

The paper's argument and analysis are developed in five sections. Drawing on the globalcity/world-city literature, the first section outlines the distinct and unique traits that distinguish global-cities from other large MSAs. As the principal independent variable, the global city will be identified as having seven multiple-perspective dimensions. Section two will establish inequality as the dependent variable, but will do so by noting that the type and magnitude of inequality varies widely in an American context. Further, inequality in metropolitan areas will be estimated both as overall economic inequality in American society (e.g., as measured by metropolitan Gini Coefficients) and by income-disparity ratios between very high-income earners, middle incomes and the poor. Section three lays out the methodology, which includes both a discussion of multiple regression analysis and a path analysis that provides a multi-factor 
analysis incorporating mediating variables in pathways between the global-city dimensions and inequality. The fourth section contains the results of regressions comparing the significance of global cities relative to rival hypotheses in determining economic inequality, while section five carries the analysis forward to a second stage of analysis involving a detailed path analysis. Section six contains a discussion on the overall significance of the findings and the identification of factors that aggravate the condition of metropolitan households most adversely impacted by inequality. The final section is the conclusion which provides essential takeaway points and offers further avenues of research.

\section{Global Cities: The World's Transactional Platforms and Urban Gateways}

Most of the discussion on equity issues and socioeconomic inequality are attributed to factors that are national in origin (e.g., insufficiently-progressive federal tax policy, decline of American unions, shifting manufacturing mix, racial discrimination) or are regionally derived (e.g., resistance to anti-discrimination enforcement in southern states), thus causing a focus on generalized impacts not specific to metropolitan places. This research on global cities does not discount these macro factors, but it does argue urban settings are at least as important in understanding sources of inequality, especially those having impact at a metropolitan scale.

As a subtype of metropolitan areas, global cities exhibit specialized forms of economic development, resulting in distinctive outcomes, especially regarding socioeconomic equity. Some may believe that "all cities are global," but, in terms of metropolitan character, cultural robustness, innovation, and world connectedness, global cities stand apart on a comparative scale in at least three ways. These include (a) their vastly greater resource capacities to maintain global advantage, (b) their defining influence over national and international policy, and (c) their role as nexus in the "traffic" of global economic, sociocultural and political interaction and exchange. 
The significance of this uniqueness has to do with the central place global cities hold as world gateways and command platforms, influencing the character and movement of global socioeconomic flows. Beside the fiscal flows of world trade, there are also corresponding magnitudes of interaction associated with human migration, sharing of intellectual capital, world-class entertainment, multi-national processes among governments, and more. Hence, one can expect many causal factors of inequality that, although perhaps originating in the larger world sphere, have their principal appearance at the metropolitan level, and specifically in those places most tightly coupled, interdependent with, and central to globalization.

To understand what these urban places are and how they operate differently than metropolitan areas less connected with globalization, we need to identify those primary dimensions that make global cities unique. To begin, the term "global city" is most often attributed to the seminal work of Hall (1966) and Sassen (2001), both of whom argue that the global city refers to a discernible urban habitat, acting as a portal and stage for world connectivity. While others have adopted this characterization more recently (e.g., Clark and Moonen, 2013), the two early works conger the image of a place that is, at once, contemporary, international, multicultural, "wired", cosmopolitan, congested, but most especially representing a "platform" commanding and controlling geographically-boundless spheres of human activity. Hence, the global city is distinguished from others by being more than just a large metropolitan area.

Although a plethora of perspectives on the world-connected city exist using such identifiers as "international city", "weltstadt", "superstar city" and "mega-city", none promote the holistic image of a global city as a complex multi-dimensional nexus of place-based global institutions and activities. By contrast, the global city is described here as a multiple-perspectives 
construct, involving two types of urban artifact. First, the global city offers a critical mass of central functions and infrastructure associated with a world-scale assemblage of "parts". Worldwide, global cities tend to be large places because they provide thresholds in form and scale to confer agglomeration economies that enable these parts to engage across many matrixrelated activities (Guiliano, Kang and Yuan, 2019; Porter, 1996; Glaeser, 2010). Activity examples include the co-production of applied knowledge, technology innovation, symbolic creations, capital management, policy coordination, global transaction control, logistics and mobility. Secondly, the global city infuses the "on-site" cultural and political content of globalization by providing an urban milieu of scientific research and education centers, media and entertainment venues, and multicultural amenities.

Referring to these dual identities of function and content, Nyman (1996, p. 6) argues the global city is about both "the city in the world" and "the world in the city." Following this dual imagery, the individual global city should appear empirically as a strategic platform of world connectivity manifested in discrete sets of urban institutions and activities less characteristic of other metropolitan areas. A more complete discourse on specific global-city dimensions is presented elsewhere (Boschken, 2008), but the essential construct of seven distinguishing components includes the following:

1. The Spatial Dimension: Scale and Form. Global cities are more than just big cities. They exhibit a spatial configuration that achieves multiple simultaneous thresholds which provide different consortia of global actors with resource proximity, inter-actor access and correspondence, and spatial mobility. These kinds of multiple thresholds augment and facilitate interaction across a variegated matrix of corporate, non-profit and government institutions. However, instead of size per se, scale and form paint a truer picture of the spatial dimension 
connoting the thresholds criterion. Hence, the image drawn here is that of a large-scale metropolitan area having a dense conical shape (sometimes monocentric, sometimes polycentric). Empirically, this dimension is identified by a variable consisting of a metropolitan area's population and density (i.e., population/sq mi). Due to the great demand for face-to-face relationships (even in the age of digitalization) and scale economies achieved by dense arenas of collaboration (Sassen, 2001, Porter, 1998), the consortia of world actors find substantial benefit from clustering in global cities.

2. Global Command and Control. The global centrality of a metropolitan area is based in part on the area's role as a node of power and connectivity in the global economy. Taylor (2004, p. 52) argues that such areas have gathered together information technologies to become "strategic places for servicing global capital" needed in the worldwide "offshoring" of manufacturing. As a "command center" (Friedmann and Wolff, 1982), involving concentrations of financial management and other "producer-services" (Sassen, 2001), the global city is a strategic nexus of information processing and resource control operating in a world network of like places. Bringing together complex, interactive systems of cyberspace technologies and organizational power, global cities are concentrations of international banking, consulting, accounting and other economic services employed in coordinating and controlling fiscal, material and people flows on a world scale (Castells, 1996, 1989, Pilka and Sluka, 2019). Sassen adds that "a global economy has created new kinds of needs for companies: accountants specializing in Asian tax law, lawyers expert in European Union regulation, marketers who understand Latin America" (quoted by Badger, 2017).

This command-and-control dimension, however, can be seen in two ways. First, as emphasized by the world-city system perspective (Taylor and Lang, 2005; Anderson and 
Beckfield, 2004), producer-services firms create and maintain global networks to communicate among themselves and affiliates in branches located worldwide in global cities. "As such, these global service firms 'interlock' the cities in which they have presence" (Taylor and Lang, 2005, p. 3), such that "the most basic measure of a city is its connectivity in relation to all other cities in the matrix" (Derudder, et al, 2003, p.878). In this way, global command and control networks are finite and mostly limited to global cities (Storme, Derudder and Dorry, 2019).

However, from another perspective, a command center's principle role in global economics is to facilitate and control physical and economic resources worldwide. This includes dispersed manufacturing locations (often in emerging countries) which usually are separate and remote from global-city command centers (Sassen, 2001; Friedmann, 1986; Hymer, 1971). In this second way, the connectivity, information flows and relational power of a command center are likely to be different from or even greater than estimates made from relational data for a matrix of global cities alone.

Both of these ways suggest that, unlike previous eras where a metropolitan area's economic centrality was identified principally by a dominant position in actual manufacturing and materials flows in surrounding hinterlands, today's global city is a dominant site for orchestrating the post-industrial economy of symbolic transactions, knowledge management and capital accumulation. Hence, empirically, this dimension is measured by a factor representing both views: (1) the global city's connectivity to the world network of economic command and control (data from the GaWC - Global and World Cities Network) and (2) the presence of command-and-control firms in a global city (data from U.S. Census, using NAICS).

3. World Research Crucible. Tightly coupled with the agglomerated platform of command-and-control is the omnipresence of a robust world center for multidisciplinary research 
and development. Supporting the policymaking capabilities and global reach of the command and control platform, this research-purposed crucible is composed of an institutional maze of world-ranked universities, global technology firms, government labs, and tax-exempt research organizations acting together as a consortiums of research and development. Adding to the centrality of global cities, this crucible produces the educational infrastructure and scientific knowledge to an evidence-seeking "global village" of corporate and public policymakers (Muro, and Whiton, 2019a; Brint, 2001; Kerr, 1963). To capture this dimension empirically, a factor is used consisting of an MSA's total number of world-ranked universities (Times Higher Education, 2019) and the total number of patents granted in the MSA between 2000 and 2015 (U.S. Patent \& Trademark Office, 2019).

4. Global Entertainment Machine. Although the principal example of this dimension is often mistakenly thought to be sports venues and stadia (Nelson, 2001; Coates and Humphreys, 1999), the entertainment activities having far greater and broader significance for an MSA's global connectivity include cultural festivities, performing arts, media resources, museums, restaurant districts, international retail complexes and "urban wilderness" (Clark, 2004; Abrahamson, 2004; Florida, 2012). Empirically, the dimension is measured using MSA-level Census data for arts, entertainment and recreation venue receipts (i.e., Census data: NAICS 71).

5. Global Center of Multicultural Exchange. In addition to its place in worldwide movements of information, money and materials, a global city is also a nexus for multicultural migration, integration and intercultural exchange (Sassen, 2004; Rath 2002; Tajbakhsh, 2001). As a characteristic of place, multiculturalism is part of the "world in the city" (Nyman, 1996). This dimension receives much of its distinguishing presence and visibility from the employment needs of the global platform, including families of a professional class of managers and 
scientists, and contingents of less-expensive skilled labor needed to support global platform functions (Beaverstock, 2004; Abrahamson, 2004; Perkins, 1997). It is further reinforced by ethnic and lifestyle diversity which enlarges tolerance of civil liberties and international experiences of those immersed in the global scene (Clark and Hoffmann-Martinot, 1998).

Making multicultural awareness an everyday experience, the global city is a place of greater opportunity to share diverse heritages whether they are found in traditional "showplace" ethnic neighborhoods or the evolution of culturally hybridized settings (Tajbakhsh, 2001) in places of work and play. The empirical measure used here to represent a multicultural environment is the number of foreign-born living in the MSA.

6. International Transportation Gateway. International travel and worldwide movement of goods are also distinguishing features of globalization, indicating a metropolitan area's connectivity to foreign lands. In making decisions about sites strategic to command and control of international flows, corporate-services firms and manufacturers found that a few strategic access points or gateways in the global logistics network provided them with superior efficiencies (esp. in time and scale).

Two aspects reflect this gateway benefit. First, global cities are distinguished by the cosmopolitan clientele of their global gateway airports (Derudder and Wilcox, 2005; Matsumoto, 2004; Keeling, 1995), which is measured here by the annual number (inbound + outbound) of airport international passengers (U.S. Department of Transportation, 2017). Second, global cities are distinguished by the flow of container traffic at "load-center" seaports located in or near the metropolitan area (Erie, 2004; Boschken, 1988, 1985; Danielson and Doig, 1982). The metric for this activity is the dollar value of international cargo (I + E) passing through MSA seaports (U.S. 
Census Bureau, 2017). A factor consisting of both international passengers and maritime cargo data is used as the empirical indicator of the gateway dimension.

7. Rail Transit Mobility Infrastructure. Since the 1980s, rail transit (both heavy and light) has gained stature as a distinguishing feature of global cities (Boschken, 2002). Although recently upended by declining subsidies and the COVID-19 pandemic, rail's success (as compared to buses) is marked by its essential role in defining the global-city as a highly mobile and accessible place necessary to support other global-city dimensions. Here, transit infrastructure in the MSA is indicated by rail-based capacity measured as a factor consisting of annual total vehicle revenue miles and total system track miles within the MSA (Federal Transit Administration, 2017).

Although these seven concept-based dimensions may not capture all that makes up a global-city milieu, they do provide a robust multiple-perspective characterization of such places. Moreover, they focus on key aspects that make a global city distinctive. "In short, it is not simply the whole city that is global; it is a specific set of vectors" (Sassen, 2020). For the purpose of empirically addressing the global city's association with socioeconomic inequality, these dimensions are factored into a single construct variable empirically representing such places as holistic metropolitan settings composed of reinforcing components. The results, as shown in Figure 1, indicate the global-city factor to be highly correlated with all seven individual dimensions, each of which exhibits a correlation (r) with the factor of .90 or higher (signif. at the .01 level).

\section{[FIGURE 1 ABOUT HERE]}

The resultant factor values for the study's sample of 53 metropolitan statistical areas (MSAs) represent the independent variable in the subsequent empirical analysis. As shown in 
Figure 2, these values are scaled to reveal significant variance between global cities and those that are not. In particular, the figure graphically shows two metropolitan areas to be primary or "alpha" global cities in the U.S. (New York and Los Angeles), two more (Chicago and the San Francisco Bay Area MSA) that are secondary or "beta" global cities, and 5 others (Washington DC, Miami, Philadelphia, Boston and Houston) as tertiary or "gamma" global cities that hold factor values of sufficient magnitude to make them appear more like global cities than like the 44 remaining MSAs in the sample.

[FIGURE 2 ABOUT HERE]

\section{Inequality in Urban America}

The meaning of socioeconomic inequality often suffers from its "blurry nature," due in part to "a patchwork of arguments" (Rothman, 2020). Notwithstanding that ambiguity, it is clear that socioeconomic inequality denies the notion that the U.S. is a homogenous society mostly made up of "median" individuals and households. Indeed, inequality exists in the relative condition of heterogeneous individuals or households and their differential access to life opportunities, resources, upward mobility, societal stature, cultural centrality, institutional fairness, and other fruits of life. As seen in a voluminous contemporary literature, its meaning is multi-dimensional (e.g., Glassman, 2019) with many component parts that share significant overlap in conceptual space. For example, most of this literature agrees with the notion that inequality is an extant societal condition with polarizing outcomes often reinforced by geographical distribution and residential sorting. Agreement on what aspects of inequality should be emphasized, however, is another matter. For example, the caricature of inequality ranges across several dimensions, including but not limited to the following: 
1. Cultural inequality focused on distinctions based on racial/ethnic, gender, religion, and intergenerational differences. This aspect of inequality gains currency and salience from generations of racial unrest and the 1970s "post-materialism" influx of variant "lifestyles" (e.g., foreign immigrants, hippies, women's lib, LGBTQ community) that posed a perceived competition to the status quo and, in turn, were subjugated by "populist" backlash groups "representing" America's traditional norms and prevailing values (Inglehart and Norris, 2017; Hooker and Tillery, 2016; Silver, et al, 2019).

2. Political inequality focused on distinctions resulting from elitist bias in institutional process and policy design (e.g., access discrimination, dominant interest-group and corporate lobbying, partisan polarization), voter-access manipulation, and gerrymandering. Its salience lies in the "asymmetric" nature of political power and its corresponding alignments in governance and policy outcomes (Gilens and Page, 2014; Pierson, 2016; Mounk, 2018; Sunstein, 1999). 3. Social-class inequality focused on distinctions of hierarchical stratification according to educational achievement, professional employment status, residential location, and deference to family heritage and "old boy" networks (i.e., elitism/cronyism). Unlike inequality in a static caste or traditional class, it gains saliency from status insecurities inherent in the vagaries of a transient mass society (Nisbet, 1966). In the case of a "white working class" (Gest, 2016), inequality may be perceived as having diminished social relevance, resulting from eroding "traditional" social norms and a feeling of being "strangers in their own land" (Hochschild, 2016). Such feelings of inequality may experience intergenerational transfer as parents of lesser class status forgo educational opportunities for their children, including organized extracurricular activities (e.g., Weininger, Lareau and Conley, 2015). 
4. Economic inequality focused on distinctions based on income and wealth, job skills, intergenerational economic mobility, and wealth opportunities bequeathed by family legacy. It gains saliency from the elitist bias in determining pay scales and implicit in the "increased skewness in the right-tail of the [wealth] distribution" (Katz and Krueger, 2017, p. 382). Economic inequality gains currency because it "has risen at a stupefying rate over the past couple of decades" (Florida, 2017, p.82).

Although some argue to the contrary (e.g., Inglehart and Norris, 2017, p. 446), these different forms of inequality are highly interdependent, probably mutually reinforcing, and behave holistically (Duncan and Murnane, 2011; Hacker and Pierson, 2014; Weininger, Lareau and Conley, 2015; Stiglitz, 2016; Inglehart, 2016). They are also evident in ground-level realities. Reflecting access barriers and blocked opportunities, inequality may therefore simultaneously manifest in such equity conditions as gender and race discrimination, diminished educational achievement, family heritage of poverty, voter suppression mechanisms, employment-income and household-wealth differentials, and variant child-rearing patterns (e.g., unsupervised after-school amusements vs. intensive participation in organized extracurricular and child-enrichment activities). Such access barriers and blocked opportunities not only regard the current workforce but also affect intergenerational mobility, causing a perpetuation of the condition over time (Chetty, et al, 2016). Moreover, the simultaneity of different inequality forms is often spatially observable in the clustering of geographical segregation within metropolitan areas (Hulchanski, 2010), resulting from residential sorting, another perpetuation factor (Bischoff and Reardon, 2013).

Even so, if one dimension stands out as more central than others, it would be economic inequality. It also may stand as a useful empirical proxy for the other less-quantifiable 
dimensions. A principal argument for why economic inequality may legitimately exist in competitive arenas comes from marginal productivity theory. Specifically, it asserts that, under conditions of perfect competition, everyone participating in the allocation/production process earns a fiscal compensation equal to his or her marginal contribution to that process. By associating higher income with greater contribution, the theory sees resultant differential compensation as a necessary and useful outcome of systemic economic integrity and "fairness". Nevertheless, some argue that what makes inequality an issue is its "economic unfairness" (Starmans, Sheskin and Bloom, 2017, Rothwell, 2019). As Stiglitz (2016) notes, competition is less than perfect, creating distortions in pay and contribution based on extraordinary market transitions, market externalities, tax policy, monopoly behavior, and such extra-market factors as exploitation and discrimination influences.

Under such conditions, many have associated the emergence of Post-Cold War globalization and existent anti-competitive oligarchic devices as sources of current economic inequality, where nearly all workers except the top one percent of earners (principally corporate CEOs and their senior management) have experienced flat to declining incomes over the last five decades (e.g., Saez, and Zucman, 2014; Chetty, et al, 2014; Piketty, Saez and Zucman, 2016; Stiglitz, 2016; Katz and Krueger, 2017; Englehart and Norris, 2017; Mishel and Schieder, 2018). During this same period, the disparity in CEO-to-worker compensation dramatically increased, as seen in contrasting the 1965 income ratio of 20-to-1 with the 2017 ratio of 312-to-1 (Mishel and Schieder, 2018).

In the case of the top .01 percent of income earners, "its share of national income grew by roughly 600 percent in the past 40 years" (Saez, 2015), making the U.S. "an outlier among most affluent democracies... with respect to the hyper-concentration of gains at the very top of the 
income distribution" (Piketty, 2014). Adding accumulated wealth to annual compensation not only makes the contrast even more stark, but also stifles capital investment that would buoy up wages in a growing economy. To this point, Mian, Straub and Sufi (2020) argue that "[T]he savings glut of the rich...has not [emphasis added] been associated with an increase in investment, [but] instead has been linked to substantial dissaving and large accumulation of debt by the non-rich."

The current picture, then, is of a great transformation from a more leveled income distribution and significant upward intergenerational economic mobility prior to contemporary globalization's emergence (where average and median incomes approximated each other), to a post-emergent globalization circumstance of "winner-takes-all" outcomes involving a highly skewed income distribution. In light of the central tenant of perfect competition, such polarized inequality anchored in "higher CEO pay does not reflect correspondingly higher output or better firm performance [and] means that the fruits of economic growth are not going to ordinary workers" (Mishel and Schieder, 2018, p. 2). Moreover, when taking into account the downward slope of intergenerational mobility since the onset of globalization, economic inequality appears even more ominous going forward (Chetty, et al, 2016).

Regarding differential geographical impact of such conditions, the essential purpose of this research is to ask whether global cities, by the embodiment of their seven dimensions in the centrality and connectivity to globalization, are more likely than other metropolitan areas to accentuate or compound the problem of economic inequality. Thus, for comparing metropolitan areas, the measurement of economic inequality can involve numerous indicators, depending on whether one's focus is (1) on income vs. wealth, (2) on overall economic equity, or (3) on the economic disparity between different slices of the metropolitan employment structure 
(Glassman, 2016). In this study, the focus is on household income data reflecting both overall inequality in a metropolitan area and on the MSA's disparity between income levels.

In the case of overall income inequality, the Gini Coefficient Index is the most commonly used indicator (Lakner, et al, 2016; Glassman, 2016; Florida, 2017). Gini is defined as an index representing skewness of income distribution for the entire working population. Based on a Lorenz Curve model, it is a closed-scale measure of values between 0 (where everyone receives an equal share) and 1 (where only one recipient receives all the income) (U.S. Census Bureau, 2018; Dorsch and Maarek, 2019, Lerman and Yitzhaki, 1984). As an example, in 2018, Gini for the total U.S. working population stood at 0.485 , which was among the world's highest for developed countries.

In the case of disparity among income levels, ratios between extremely high-income households (e.g., top $0.01 \%, 1 \%, 10 \%$ ), and lower household percentiles (e.g., lowest 10\%, 20\%, $50 \%$ ) are used. Specifically, this study includes (1) the 90-10 income disparity ratio, composed of incomes higher than 90 percent of all MSA households divided by the incomes of those poorest households (poverty-stricken "underclass") at the $10^{\text {th }}$ percentile (U.S. Bureau of Labor Statistics, 2015); (2) the 95-20 income disparity ratio, composed of the top 5\% of income earners and the lowest quintile of very-low wage earners and unemployed underclass (Berube, 2018); and (3) a 99-50 disparity ratio, composed of the top $1 \%$ of household incomes (composed mostly of corporate CEOs) and median incomes representing "middle class" households (U.S. Census, 2018; Sommeiller and Price, 2018; Pew, 2018).

\section{Methodology: A Two-Level Cross-Sectional Analysis}

The analysis of data is organized into two levels of results. At the first level, essential questions pertain to whether the global city matters statistically in explaining outcomes of 
inequality, and if so, by how much relative to independent rival hypotheses. These questions are addressed according to "direct" relationships between metropolitan areas and the four inequality indicators. This is done first through analysis of simple correlation between global cities and inequality indicators, and then by a multiple regression analysis comparing potential causal impact of global cities on inequality with three independent rival theses. These rivals include:

1. Manufacturing Presence. When speculating about factors affecting metropolitan inequality, manufacturing sectors (NAICS 31-33) are more frequently associated with wage stability in a skilled labor force when compared with most service sectors. Hence, the thesis generally argues that a strong manufacturing presence in an MSA's total employment mix is inversely related to economic inequality (e.g., Emmenegger, et al, 2012; Levy and Murnane, 1992). Furthermore, such research argues that in many major metropolitan areas where "deindustrialization" has reduced the presence of manufacturing jobs, blue-collar workers have been forced to shift to lower paying jobs in the service sector. It is thus argued that a reduced manufacturing presence resulting from "job polarization" or "hollowing effect" increases income inequality, especially affecting "routine" middle-class jobs (e.g., Jaimovich and Siu, 2018). As a rival variable, manufacturing presence is measured by the ratio of MSA manufacturing jobs to an MSA's total employment base. Data is from the U.S. Bureau of Labor Statistics (2017) and the U.S. Census (2018b). Variable correlation with the global-city factor is insignificant $(r=-.093)$

2. Technology-Driven Productivity. The second rival focuses on the impact of industrial or manufacturing technologies on inequality, where technological adoption displaces mostly blue-collar jobs (Harrison, 2017; Acemoglu and Restreo, 2019), forcing "wages to face downward pressure" (McKinsey Global Institute, 2017). Recent research considers "how labor immiseration may result from a wave of 'brilliant machines' [and] various channels through 
which automation impacts labor's share of output" (Artor and Solomons (2018). One of the more prominent arguments for this relationship begins with "a superstar firm explanation" (Artor et al, 2017). It says that where industry concentration is caused by differential adoption of technology within an industry (i.e., less technology-sophisticated firms are eliminated by more sophisticated ones either by acquisition or exit), the resultant productivity gains are accompanied by lower aggregate manufacturing jobs relative to aggregate industry value-added sales (Artor and Salomons, 2018). As structural unemployment accompanies this shift, making comparable employment less available, displaced workers may be limited in choice between lesser-paying jobs and unemployment (either of which contributes to income inequality).

However, not all technologies have the same effect. For example, although robotics and software have significant impacts on blue-collar workers (i.e., substituting predictable and routine tasks), artificial-intelligence (i.e., computer-discretionary probing for patterns within ambiguity-prone situations) appears to have its main adverse impact on highly-skilled workers (Acemoglu and Restrepo, 2020; Webb, 2020; Muro, Maxim and Whiton, 2019; Muro, Whiton and Maxim, 2019). For inequality, therefore, the automation effects of robotics and software are the central concern. In this study, technology-driven impacts are measured in terms of comparative manufacturing productivity by a ratio between an MSA's total manufacturing revenue and its total manufacturing employment base (U.S. Census, 2018b). This ratio's correlation with the global-city factor is insignificant $(\mathrm{r}=-.073)$.

3. Union Influence. In the tradition of unions providing a "worker voice" (Chiarenza, 2018) in society, a plethora of research examines how unions affect inequality. But their frameworks vary widely, and therefore, not all possible relationships are accounted for here. Instead, this study uses a perspective focused on union power in the overall MSA economy, 
sometimes referred to as "union density" (e.g., Farber, et al, 2018; Mosher, 2007). It is a perspective sometimes associated with a narrower one focused on union/non-union wage differentials (e.g., Card, Lemieux and Riddell, 2004; Card 1998). In general, though, the central argument is that union power or density inversely influences inequality (i.e., the greater the union power, the lower the inequality). The variable is quantified as a ratio of union-membership in an MSA relative to the MSA's total employment base. This variable's correlation with the global-city factor is insignificant $(\mathrm{r}=.172)$.

Beyond these three rivals, no attempt is made to exhaust all possible competing theses. It is also noted that for both global-city status and its rival theses, the larger specter of "globalization", both economic and social, exerts numerous indirect influences which are not accounted for. This is especially symptomatic of effects from international trade and protectionism (e.g., Harrison, 2019). Hence, the subsequent regression models include a constant which contains the backdrop of unexplained variance (Berk, 2004), some of which is likely caused by "globalization."

The second level moves the analysis to examination of plausible causal pathways that more discretely link global cities with economic inequality. Through use of a simplified nonrecursive path analysis, it identifies those mediating or intervening variables that appear to populate important pathways associating global cities with inequality. Through path analysis, a more complex and informative picture of potential causes may be found in the urban conditions, resources and activities not only induced by the seven distinctive global-city attributes (i.e., composing the global-city factor), but which also conceptually and empirically set it apart from other metropolitan areas. In this sense, the path analysis is used here as a means of augmenting constructs about causation rather than proving causation. 
All data are scalar and have been compiled for 53 of the largest U.S. MSAs, the biggest of which contains a population of nearly 20 million and the smallest of which is just under a million. All data were acquired from existing publicly-available sources, including the U.S. Census, U.S. Bureau of Labor Statistics, Brookings Institution, Pew Research Center, The Urban Institute, and numerous research papers. Variables were intended to be of the same time period, but corresponding data were not jointly available for a single common year. Hence, the data sample represents proximal years, specifically years 2010 and forward, with the majority of variables falling within a time interval of 2015 to 2020.

\section{Results}

The most basic question of this research asks whether global cities, on a continuous scale with other metropolitan areas, are associated with the problem of urban economic inequality. As shown in Figure 3a, the answer appears to be yes, and to a very significant degree. Global-city status exhibits a significant and positive correlation with the overall magnitude of inequality as measured by the Gini Index ( $r=0.56$; signif. @ .01). This correlation is borne out graphically as shown in Figure 3b, where a scatterplot displays the 53 MSAs according to the global-cities factor juxtaposed with the Gini Index. Moreover, this result is consistent with other global-city research using Gini (e.g., Monaghan and Ikeler, 2014).

\section{[FIGURES 3a and 3b ABOUT HERE]}

In addition, with respect to income disparities within a metropolitan social structure, Figure 3a shows the largest correlations for global-city status are with the 90-10 income ratio, which focuses on extreme income poverty $(r=.52$; signif. @ .01), and with the 99-50 ratio, which singles out disparity between the top 1 percent of income earners (mostly corporate CEOs) and middle-class workers $(\mathrm{r}=.55$; signif. @ .01). The least significant correlation is with the 95 - 
20 ratio $(\mathrm{r}=0.39$; signif. @ .01), perhaps indicating uneven impact of global-city status across the metropolitan social structure. Supporting similar results elsewhere (e.g., Abel and Deitz, 2019), these findings draw a picture of income disparity specific to global-city status involving an elite class of households drawing highly disproportional fiscal shares from the economic system in stark contrast with the lesser receipts of both the working poor and the middle-class household.

Having affirmed this most basic relationship between global-city status and inequality, the second concern is to decipher the causal impact global cities have on inequality relative to rival hypotheses independent of global-city status. As shown in Figure 4, the global city factor is comparatively much more significant than the rival hypotheses across the four inequality measures. With regard to the Gini (overall inequality), the global-city factor is the only variable that holds significance as a comparative causal agent $(\mathrm{t}=5.53$, signif. $=.000)$. Union influence is also near significance and in the predicted direction $(\mathrm{t}=-1.70$, signif. $=.096)$.

\section{[FIGURE 4 ABOUT HERE]}

Regarding the distribution of income disparities specific to parts of the socioeconomic structure, the most significant relationships are found in two of the three disparity ratios. In the disparity involving the poorest households (measured by the 90-10 ratio), the results show global cities as the only influence of significance and is in the predicted direction $(\mathrm{t}=4.86$, signif. $=$ .000). In the disparity involving middle-class incomes (the 99-50 ratio), where the top 1 percent walk away with vastly larger shares than those with median incomes, the results again show global cities to be very significant as a causal agent $(\mathrm{t}=5.42$, signif. $=.000)$. The only other variable near significance is union influence, and it is in the predicted direction $(\mathrm{t}=-217$, signif. $=.035)$. 
Of the three disparity ratios, the 95-20 ratio shows very low significance (model signif. $=$ $.059)$. Even here, though, global-city status remains significant $(\mathrm{t}=2.80$, signif. $=.007)$ in contrast to the other causal agents which are not. A possible explanation for the much lower significance of this model relative to the other two is fleeting but may have something to do with the erosion of middle-class employment in global cities, and consequent migration to low-wage employment in service sectors (Autor and Dorn, 2013).

\section{Path Analysis - Tracing Plausible Causal Linkage}

The regression analysis shows global cities having a comparatively stronger causal influence on inequality than elements characterized by the rival hypotheses. Specifically, it indicates that the more a metropolitan area exhibits the traits of a global city, the greater the level of inequality present. Why should this be? The most direct answer invokes the persistent dichotomy between economic development and socioeconomic equity. Comparatively, global cities appear to have a greater and more intense focus on competitive economic development by virtue of their greater connectivity with, centrality to, and dependence on globalization. In the context of dichotomy, socioeconomic equity is the likely loser.

But an extended answer to this question may lie in seeing the global city as more of a capability-enabling habitat than simply as a direct cause of inequality. That is, even though the global-city typifies an enriched, multiple-perspective context for understanding place-based inequality, it may be more accurate to see the global city as a place-based "umbrella" for certain mediating or intervening circumstances found within it that are causal to inequality. For example, the global-city makeup, characterized by its seven distinguishing factor components, might be construed as a conducive habitat for certain kinds of globally-relevant economic 
development motives, cornerstone resources and an employment structure skewed to optimize a global city's world centrality and connectivity.

To drill down more deeply on this question, a path analysis offers an exploratory method to trace cause through pathways of intermediating variables linking the global-city factor with the four indicators of inequality. As a note on interpretation, all pathway variables were designed around existing research-informed constructs, which may be empirically measured in several ways. Hence, depending on measurement instrument, some constructs may generate interpretations contrary to this study's causal argumentation. This said, Figure 5 shows a path analysis detailing a picture of primary mediating relationships driven by variables having theoretical underpinnings suggesting their connection to global cities. The role(s) each conceptually plays in passing along or accentuating the global city's effect on socioeconomic equity is shown empirically by non-recursive pathway correlation notations. Although no attempt is made to exhaust all possible mediating variables, the analysis does focus on the following three aspects differentially characteristic of the global-city setting.

\section{[FIGURE 5 ABOUT HERE]}

1.Cornerstone Resources for Global-Advantage: The global city attracts very significant specialized resources that are particularly instrumental to maintaining its connectivity and centrality to globalization. Comparatively, such differentiating resource concentrations are not found in similar magnitude across other metropolitan areas. Although there may be others of relevance, the path analysis identifies three of particular note, each having a significant correlation with the "umbrella" global-city factor. They include:

A. Agglomerations of Innovation Resources (with Global-City Factor: r=.80, signif @

.01 level). Despite advantages of internet communications, the spatial agglomeration or 
clustering of common and interdependent tasks provides in-person dynamics and multisensory interaction essential to innovative behavior. The result of this mutual proximity creates a decided "competitive advantage" favoring creativity and innovation (Giuliano, Kang and Yuan, 2019; Porter, 1996, 1998; Saxenian, 1996). On this point, global cities are acknowledged as both wellsprings of development capital and agglomerations of "Schumpeterian entrepreneurship" (i.e., the theory of creative destruction), discovery, and avant-garde invention for the global economy (Adler, et al, 2018; Muro and Atkinson, 2020).

Furthermore, through their disproportional concentrations of capital and other advanced producer services, global cities are citadels of local support and infrastructure for innovation (i.e., as characterized by the 7 global-city dimensions). Moretti (2019) argues that "despite the higher costs" of global cities, inventors and creators prefer such places because they provide greater global economic visibility and access, and better support for larger agglomerations of innovation. Reflecting this symbiotic circumstance, data shows that between 2005 and 2017, global cities were the principal centers of innovation resources, having both the largest cumulative amounts of venture capital invested and the number of new-firm startups (Florida and Hathaway, 2018).

At the receiving end of this funding and startup activity are agglomerations of individuals, typically having advanced technical and design skills (Muro, 2020), who are engaged in a multidimensional "creative economy" (Florida, 2012). Not to be confused with established or traditional industries, these agglomerations are inter-group collaborations which do not conform to conventional industry norms and bureaucratic behavior. Going further, Clark and Silver (2016) refer to these resource agglomerations 
as urban "scenes" consisting of atmospheres that "cultivate skills, create ambiances and inculcate commitments" to habits of experimentation and imagination (pp. 111-112). Huggins and Izushi (2009) make an association of such agglomeration of "intellectuals" with an MSA's "knowledge competitiveness" worldwide. Speaking to magnitudes of difference among metropolitan areas, a Brookings study argues that "agglomerations of highly skilled workers and...the innovation sector has...helped spawn a growing gap between the nation's dynamic 'superstar' metropolitan areas and most everywhere else" (Atkinson, Muro and Whiton, 2019).

Quantifying such agglomerations of innovation resources is done by calculation of a factor, composed of three variables making up 100 percent of the single-factor variance. The first is an estimate of the cumulative dollar investment of venture capital in an MSA between 2005 and 2017 (component $r=.85$ ). It is a measurement of differential size of innovation resources specific to each MSA in the 53-subject sample based on data from Florida and Hathaway (2018). The second component addresses the MSA's startup ecosystem and is called the "Startup Complexity Index" (component $r=.98$ ). The SCI data is from Liu and Parilla, (2019), who create the index from an interaction variable combining "startup diversity and startup ubiquity." Diversity represents the variety of technology categories in which startups are engaged, while ubiquity represents their omnipresence in the most advanced innovation industries. The third factor component is a human-resources variable and is defined as the number of employees working in "advanced industries" (component $r=.87$ ). Such industries are characterized by Brookings as heavily invested in technological innovation and employing "skilled 
technical workers to develop, diffuse, and apply new productivity-enhancing technologies" (Muro, et al, 2015).

With their larger presence in global cities, the agglomeration of innovation resources bears heavily on the surrounding metropolitan culture, economic character, and production mix. Although such agglomeration may peak the aspirational desires of many inventors, it also forms the foundation for a more complex understanding of how global cities might be different in creating and harboring conditions for greater economic inequality. For example, in addition to indirect path effects, the direct effect of this mediating variable on inequality is observable in path correlations for overall inequality as well as the three disparity ratios (i.e., for Gini, $r=.45$; for $95-20, r=.43$; for $99-50, r=$ .66 ; for $90-10, \mathrm{r}=.81$; all significant at the .01 level). The literature suggests two, possibly related, ways to understand this predictive strength of agglomeration directly on inequality.

First, empirical work has indicated that "skill-based technical change" fostered by the innovation agglomerations leads to higher inequality (Giannone, 2017; Card and DiNardo, 2002). By comparing divergent wage-level experiences among metropolitan areas for both high- and low-skilled workers, this line of research found that since 1980, skill-based technical wage growth and agglomeration of innovation resources were greatest in global cities. At the same time, wages for low-skilled and non-skilled jobs in the global city, many of which were peripheral to the to the increasingly dominant innovation clusters had stagnated. This divergent income experience appears to have led to a direct pathway for higher inequality. 
Second, in light of the greater concentrations of innovation resources in global cities, there also may be a greater socio-cultural appreciation in such cities for intellectual property and "technology entrepreneurship", potential new enterprise frontiers, and hightech worker importance (Liu and Parilla, 2019). Benner and Feng (2020), argue further that such an appreciation for entrepreneurship encourages acceptance of an edict to "move fast and break things," that willfully creates a "pattern of generating poverty jobs." With such disregard for socioeconomic consequences, it is nevertheless conceivable that many global-city inhabitants (and public policymakers) might be more enamored with and supportive of their MSA's creative scenes and innovation ethic than they may be sympathetic with the plights of those peripheralized in traditional industrial and service employment. If accurate, such distortions in preferential appreciation might co-explain the significant direct effect of agglomerated innovation resources on all the economic inequality metrics.

\section{B. Sustainable-Development Investment (with Global-City Factor: $r=.49$, signif @ .01}

level). The signature marque of a global city is its high-visibility for world-centered economic development. However, for global logistics and mobility reasons (both historical and current), U.S. global cities typically are also coastal cities, where ecological complexities of land, air and sea overlap. Although an important notation for global cities, all urbanized metropolitan areas are subject to significant confining pressures of a biodiverse ecology. Hence, this combination of development needs and ecologicalsystem integrity places all such MSAs at the nexus of a complicated sustainability paradox (Boschken, 2013; Marshall, 2005; Turner, et al, 1996). 
Perhaps best understood in the context of a "social-ecological system" (Ostrom, 2009), this paradox involves interdependencies between resource users, ecological supplies and institutional gatekeepers. In one subsystem are economic development demands of urbanized areas, evidenced by immense building scale, differentially high consumption patterns, a dominant corporate growth orthodoxy and trans-territorial spillover effects. On the environmental-resources side is a dynamically fragile and biodiverse ecology, consisting of complex interdependent webs of terrestrial, aquatic and atmospheric subsystems that sum to an evolving ecological carrying capacity. Worse still, much of the ecological web lies outside the control of metropolitan areas, including environmental services. Hence, the social-ecological systems model provides an important perspective and awareness of institutional dependency on resource scarcity and the implications for maintaining positional advantage in the global economy.

Faced with the paradox of subsystems, an MSA's governance processes seldom direct policy-program actions toward sustainability in a holistic fashion or in-toto scale. Consequently, metropolitan areas do not implement sustainability strategies comprehensively. Instead, they incrementally engage in implementation programs based on a previously-designed strategy for overall "Sustainable Development" (see, for example, Burns, 2016; Brose, 2014; Parkin, Sommer and Uren, 2003), Moreover, the initial strategy design stage involves comprehensive commitments in concept but not to detailed or holistic cost obligations. Because of the kaleidoscope of often unrelated programmatic alternatives that could be consistent with a sustainable-development strategy, cost considerations are reserved for program-specific evaluation at the implementation stage, involving discernable program-specific commitments. 
Even with this incremental-program approach to sustainability costs and commitment, global cities have comparatively greater fiscal and technological advantages over other MSAs that likely better enables and disposes them toward investing in highimpact and high-visibility aspects of sustainable development. In addition, a global city's worldwide presence of innovation agglomerations may auger for the application of hightech solutions to address wicked problems associated with the paradox in some highlyvisible and publicly-discernable ways.

Many environmental issues are subsumed under sustainable development, but by virtue of different MSA locations, not all issues of sustainability are pertinent to or addressable by all metropolitan areas in equivalent ways. Moreover, some environmental programs are universal to all MSAs, but consist of a vast array of "apples and oranges" having little management standardization. Municipal solid waste is a case-in-point, in part because it covers a number of "recyclable" and waste categories defined and addressed by MSAs differently. This presents a methodological quagmire for broad inclusion of programs for this research.

Nevertheless, in seeking generalizability to sustainable development, the study identifies a single program germane to all MSAs to illustrate significance of comparative investment in environmental resources. This program is called "clean energy" (Rabeiro, et al, 2019), and it focuses primarily on energy supply and utilization efficiency in reducing climatic and atmospheric effects of "urban metabolism" (Cui, 2018; Broto, et al, 2012; Wolman, 1965). As one of the global city's cornerstone resources for global advantage, sustainable clean energy therefore speaks to a global-city's penchant for command and control over global markets, especially in cases of dependency on foreign 
resource suppliers (e.g., fuels). It is also plausible that this agglomeration transfer of support extends to energizing community enthusiasm for high-tech applications to sustainable development.

Data for the variable is from the annual clean-energy "scorecard" produced by the American Council for an Energy-Efficient Economy. Consistent with the aims of sustainable development, the scorecard is an index based upon the assessment of metropolitan area commitments to policies and investment incorporating advanced technologies to address air quality and anthropogenic-caused global warming. It is therefore consistent with the application of technology to ecological systems to produce more economic output with less draw-down on environmental resources. The fact that sustainable clean energy has a larger presence in global cities, where innovation agglomerations are also the most prevalent, suggests opportunities for technology transfer may be feeding sustainable energy development (between these two cornerstone resources, $r=.73$, signif. @ .01).

In addition to indirect effects of sustainable development on inequality, sustainable-development resources also appear to have a limited direct effect. Although not appearing to have significant relationships with the Gini Index and two of the disparity ratios, sustainable development does have effect on the 90-10 ratio which measures a disparity gradient between the very affluent at the top of income distribution and the working poor $(\mathrm{r}=.68$, signif. @ .01 level). Sufficient research is unavailable at this point to speculate about why this specific direct effect on income disparity exists.

C. Unauthorized Immigrants as Human Resource (with Global-City Factor: $r=.46$, signif @ .01 level). Having an industry mix dominated by global platforms of command \& 
control, research \& development, and entertainment venues, global cities maintain an employment base skewed toward high-skilled corporate professional jobs rather than blue-collar manufacturing employment. However, attendant to this emphasis is a differentially large need for service-operations workers (both commercial and personal), characterized as low-skilled and unskilled. This class of worker is not equivalent to "wealth workers" (Muro and Whiton, 2019) who attend to needs of a corporate professional workforce, but who include both educated skilled personnel (e.g., financial advisors) and low-skilled workers (e.g., landscape maintenance).

Within this "occupational polarization" of the employment structure, high concentrations of unauthorized immigrants provide an inexpensive and readily-available supply of workers to fulfill menial employment needs (Autor, 2019). Examples include office clerical work, delivery services, food and beverage tasks, construction, urban infrastructure maintenance (commercial and residential), housekeeping, and personal services (e.g., beauty salon, gym, animal and child care). Unauthorized immigrants, pursuing non-agricultural work opportunities, find more plentiful choices in global-city economies than available in other MSAs.

Besides the draw from low-skill employment opportunities, unauthorized immigration is also induced by a global city's multi-cultural context and resultant community diversity. Most unauthorized immigrants come to the U.S. as a family household and have settled in a particular area for long periods of time (Passel and Cohen, 2009). Although most arrive from Mexico and other parts of Latin America, substantial numbers also come from South Asia, Asia, the Middle East and Africa. When 
settling in the U.S., "unauthorized immigrants tend to live... among lawful immigrants" (Passel and Cohn, 2017), often near other relatives.

In terms of location, unauthorized immigrants are significantly more concentrated in fewer places than the overall U.S. population. Contrary to beliefs that most are farm workers, Brookings found that 60 percent work and reside in the 20 largest metropolitan areas (Passel and Cohn, 2017). Nearly half of these are either global cities or MSAs near global-city status. In asking why, unauthorized immigration in global cities seems to be the result of a greater amount of unskilled work opportunities available in an economy dominated by the MSA's position as a global gateway and its connectivity and centrality to globalization.

With concentration in global cities, unauthorized immigration, as a mediating variable, appears to have a primary direct (albeit skewed) effect on income inequality. Although lacking significance for overall inequality (according to the Gini) or the 95-20 disparity ratio, unauthorized immigration is a significant predictor of the two other disparity indicators - the $99-50$ ratio $(r=.50$, signif @ .01 level $)$ and the $90-10$ ratio $(r=$ .46 , signif @.01 level).

Since the concentration of unauthorized immigration would seem to correspond with the global city's metropolitan culture, economic character, and production mix, it is conceivable that this mediating variable's contribution to inequality, albeit partial, may be related to racial/class discrimination in employment. For example, Murray and Marx (2013), show that discrimination of unauthorized immigrants is more pronounced than for legal immigrants and foreign-born citizens. The two impacted inequality indicators conceivably are the result of unauthorized immigrants being "channeled" by 
discrimination into low- and median-wage job opportunities, where they are also limited to even lower wages by virtue of employers taking advantage of their unauthorized immigration status. Concomitantly, this inferior competitive status with employers may pose a downward pressure on median and very-low wages generally, thus adding to the disparities seen in the two inequality ratios.

2. Polarized Employment Structure: As the path analysis illustrates, global cities appear to spawn disproportionately large concentrations of specialized "cornerstone resources" that provide multiple means to enhance their worldwide centrality and competitive advantage in globalization. However, these resources may also have a downside in that they appear to induce certain economic conditions of significance to income inequality. The largest of these may be the creation of a "polarized employment structure" (Autor, 2019; Jaimovich and Siu, 2018), consisting of an affluent upper middle class, a "hollowed" middle class, and an enlarged contingent of low-wage workers. Although some contend that no relationship exists between a polarized employment structure and inequality (Hunt and Nunn, 2019), the path analysis here demonstrates a rather significant and complex causal effect of polarization on inequality. To illustrate, the analysis of polarization and its effects on inequality are broken down according to the three employment components:

A. Upper Middle-Class Workers (correlation with innovation agglomeration, $r=.67$; signif. @ .01; with sustainable development, $\mathrm{r}=.67$, signif. @ .01; and with unauthorized immigration, not significant). The imagery and high visibility of innovation agglomerations against a backdrop of global platforms of command and control give global cities a distinct character and presence many find worthy of awe, respect and admiration -- distinctions not typically attributed to MSAs short on these resources and 
comparable global institutions. This esteem and reverence are often self-attributed as well as bestowed by others, but either way, refer to powerful trendsetting centers of money, technology, institutional control, and political influence.

More importantly, such stature transfers to the persona of those urban residents viewed as "having institutional connections or titles," being "close to the technology" or employed in activities requiring the systematic application of a relatively complex body of symbolic or conceptual knowledge (Reich, 1992; Brint, 2001). Such a workforce segment may include engineers, scientists, designers, artists, corporate managers, management consultants, investment bankers, marketing gurus, policy wonks, entrepreneurs, and strategic planners. What most exhibit in common are high annual incomes, professional employment, a college degree (characteristics quantified here in data from the U.S. Bureau of Census, 2018b), and resulting in affluent lifestyles. They constitute a distinct employment segment, often referred to as the "upper middle class" (UMC), a genre which has enlarged considerably in the post-1970s emergence of globalization (Boschken, 2003; Lineberry and Fowler, 1967).

With respect to high annual income, the Census sets its highest threshold category at $\$ 200,000$, which for those at or above this figure account nationwide for 8.5 percent of all households (U.S. Census Bureau, 2018c). However, if income was the only identifier of a UMC worker, the correlations for this genre with the cornerstone resources would be much higher than the three-component UMC factor used here (i.e., income-only correlation with innovation agglomerations, $\mathrm{r}=.80$; with sustainable development, $\mathrm{r}=$ .70 ; with unauthorized immigration, $\mathrm{r}=.40$; all signif. @ .01). The variance in correlation to the three-component UMC suggests that some affluent workers associated with 
innovative agglomerations may be simply "entrepreneurial" rather than college-educated career professionals. Hence, as this comparison of correlations suggest, all affluent income earners are not the equivalent of a UMC worker.

Moreover, the UMC are said to have a different behavior profile than those who are merely affluent, by virtue of being college-educated professionals. For example, the UMC are often attributed with a "public regarding" posture (Wilson and Banfield, 1964, p. 876), while the strictly affluent are more often viewed as a self-absorbed "leisure class," preoccupied with making money, and protecting their accomplishments and status-seeking "conspicuous consumption" (Veblen, 1948; Thal, 2020; Bonica, et al, 2013; Packard, 1959). Indeed, the variance in their respective correlations with innovation-resource agglomerations bares out this distinction between a UMC and merely high-income workers is palpable.

Nevertheless, even though potentially exhibiting public-regarding behavior, a substantial proportion of a global-city's UMC workers also tend to rely heavily on elite "peer-group approval" and many engage in "opportunity hoarding" (Reeves, 2018). As a genre based on intellectual capital and professional knowledge, many UMC make distinctions as well between their work and the manual labor of middle-class workers. Indirectly, this may reinforce UMC preferences for status-affirming barriers, ranging from physical (e.g., gated communities, guarded-entry high rises), social (e.g., exclusive clubs), educational (e.g., legacy admission) and public-policy (e.g., zoning, preferential taxation) to protect their genre status from erosion. It is also seen in organization behavior, where job distinctions form the basis for viewing income inequality as justified 
by a notion that higher UMC incomes reflect considerably greater contribution and importance of professional work to a knowledge-based economy.

The path correlations lend support to the argument that UMC workers are implicated in the comparatively heightened inequality in global cities. Although UMC impact is not apparent on overall inequality as measured by Gini, it is significantly associated with the income disparity ratios (with 90-10, $\mathrm{r}=.84$, signif. @ .01; with 99-50, $\mathrm{r}=.32$, signif. @ .05 ; and with 95-20, $\mathrm{r}=.29$, signif @ .05). Significance of the 90-10 ratio is particularly of note because it measures the income disparity closest to a juxtaposition between UMC workers and the working poor who are most in need of expensive tax-dependent government program support. It is unknown why UMC workers, as an essential component of a polarized employment structure, exhibit no significant impact on overall inequality (Gini Index). Further research is needed to examine what dynamics are in play.

B. Hollowed Middle-Class Workers (correlation with innovation agglomeration, $r=-.64$; with sustainable development, $\mathrm{r}=-.34$; with unauthorized immigration, $\mathrm{r}=-.52$; all signif @ .01). The term "middle class" escapes an exact science, and includes several overlapping identities such as "mid-skill workforce", "white working class" and "bluecollar worker" (Autor, 2019; Emmons, Kent and Ricketts, 2018; Gest, 2016; Hooker and Tillery, 2016; Weininger and Lareau, 2009; Inglehart, 2016). Middle class is also often associated with semi-skilled production workers, nearly all of who do not hold a college degree.

Moreover, if incomes are sorted according to social stratification, evidence further indicates a highly polarizing condition has existed nationally since the 1970s, whereas 
before that, a middle-class proportionally greater than those at the extremes of the scale, represented a stabilizing core-population bridging rich and poor (Scheidel, 2017, p. 20). Referred to as "hollowing out the middle class" (Pew Research Center, 2015), this diminished employment stature is characterized mostly by less-educated working-class people (and their offspring), often dropping into lower paying jobs, and concomitant lower wage status. The resultant trough-shaped curve since the 1970s is fundamentally different than the peak-shaped curve existing prior to globalization, revealing the emergence of "a servant economy" (Madrigal, 2019), where "a tiny but extremely wellpaid minority directs the economy, while the majority hold precarious jobs [as] gardeners, waiters, nannies, and hair dressers" (Inglehart, 2016, pp. 7-8).

A hollowed middle class is also associated with intergenerational upward mobility enabled by a college degree (Chetty, et al, 2016). Although some argue that the high school-to-college personal income differential is only nominal (Moretti, 2013) or that both high-school and college-graduate wage earners have experienced stagnate growth in real earnings (Inglehart and Norris, 2017), the ratio of college-to-high school wages reveals a substantial income differential, having increased from 1.41 in 1979 to 1.85 in 2016 (Mishel and Schieder, 2018, p. 17).

Such a widening differential also is present in household income as well as with the increasing number of family formations happening because of "educational assortative mating", where couples are drawn together by sharing the same educationlevel opportunities (Eika, Mogstad and Zafar, 2017). In the case of college-educated spouses working at professional jobs, such households have increased substantially over the last 50 years as a result of younger couples leaving behind a hollowing middle-class 
for the upper-middle-class status associated with higher education, professional employment and better incomes.

Although the middle-class construct may seem amorphous, the most common metric for measuring its presence in the employment structure is household income (Pew Research Center 2018; Berube 2018). Data for this measure is taken from the Pew Research Center (2018), which classifies middle class comparatively for MSAs as "the percent of the working population having annual household incomes ranging between 67 percent and 200 percent of the overall median household income" $(\$ 45,200$ and $\$ 135,600$ in 2016).

Put in the context of a polarized employment structure (e.g., Autor, 2019; Autor, Katz and Kearney, 2006), the middle class represents a shrinking component in both numbers and income. In metropolitan areas, its role in accentuating polarization is derived from persistent "hollowing” (Pew Research Center, 2015; Jaimovich and Siu, 2018; Emmons, Kent and Ricketts, 2018), resulting both from intergenerational upward mobility enabled by a college degree, and from persistent declines in employment demand for semi-skilled labor. In the path analysis, hollowing of middle-class employment is among the most critical elements distinguishing income inequality in global cities.

Indeed, among all the pathways significantly affecting economic inequality, those linking the global city's cornerstone resources and a middle-class workforce appear as the most powerful. Take, for example, the impact of innovation agglomerations. According to Autor (2019), the dynamic presence of "specific industries and occupations would be expected to have non-neutral impacts on the structure of occupations across metropolitan 
areas" (p. 8). In the case of a global-city's innovation agglomerations (which are populated, in part, with clusters of entrepreneurial startups primarily funded by venture capital), the polarizing impacts on the global-city employment structure is substantial, involving all three employment-structure components.

However, although the agglomeration impacts include positive correlations with two of the three employment components, an inverse causal relationship exists with the middle-class worker. Reinforcing this impact are the other two global-advantage resources (sustainable development and unauthorized immigration), which also exhibit an inverse relationship with the middle class. This strong inverse condition (not replicated in any other pathways) indicates that as "cornerstone derivatives" of global cities, the presence of global-advantage resources is subsequently contributing to a decline or "hollowing" of the urban middle-class workforce.

As established in other research, (e.g., Autor, 2019; Jaimovich and Siu, 2018; Kochhar, 2018; Florida, Mellander and King, 2017; Levy and Murnane, 1992), the hollowing effect is an essential ingredient in polarizing the employment structure across all MSAs. Nevertheless, the path analysis here shows that this polarizing effect is especially attributable to global cities, as demonstrated by relationships between the middle-class workforce and the other two employment categories (i.e., with StatusSeeking Affluent, $r=-.58$; with Low-Wage Workers, $r=-.47$ ). Moreover, much of the global city's role in hollowing the middle class and subsequent polarization appears to be due to holding competitively-superior positions in global-advantage resources. In short, even though hollowing of the middle-class is national in scope, global-city resources and institutions appear to further aggravate the condition. 
Moving to the impact of a hollowed middle-class on economic equity, all the inequality indicators show effects that are substantial and inversely related. Although research often attributes such inequality outcomes primarily to a wealthy few (especially corporate CEOs) receiving far greater shares of income than economically warranted (Mishel and Schieder, 2018; Piketty, 2014; Saez, 2015), the effect of middle-class hollowing caused by the global city's cornerstone resources for global advantage also appears to be a powerful contributor. Across Gini and the three disparity ratios, the hollowed middle-class is a significant force in the polarized employment structure associated with high inequality levels (for Gini, $r=-.72$; for 90-10, $r=-.56$; 99-50, $r=-$ .56 ; for $95-20, r=-.40$; all signif. @ .01 level). That is, the greater the decline in middleclass presence, the higher the state of economic inequality.

C. Low-Wage Workers: Ages 35 to 54 (correlations with innovation agglomeration, $r=$ .40 , signif. @ .01; correlation with unauthorized immigration, $\mathrm{r}=.65$, signif. at .01 ; and with sustainable development is not significant). As with other components of the polarized employment structure, the classification of low-wage workers has no universally agreed-upon construct that might provide a precise uncontroversial definition. Instead, the literature contains a number of partially overlapping alternatives, including "low-paid service class", "poverty jobs" and "low-wage workforce" (Florida, Mellander and King, 2017; Benner and Kung, 2020; Ross and Bateman, 2019).

Often, variance among them is based on type of work rather than strictly on household income. For example, some associate the low-wage category mostly with service jobs (e.g., office clerks, retail-sales workers, food-preparation workers, nursing assistants, housekeepers, beauticians and barbers). Others focus on heavy physical work 
(e.g., box boys and fulfilment workers, landscapers and lawn maintenance, some construction work). Most do not include "gig" workers (e.g., messenger and delivery services, cab and Lyft drivers), who, until recently, have been considered self-employed.

Regardless of the type of low-wage work included, the global city, as contrasted with other MSAs, contains the highest proportion of such workers in its employment structure by virtue of its centrality and connectivity to globalization. Moreover, according to Autor (2019), Wilson (1997), and others, many in the low-wage workforce who have entered the employment category since the 1980s have done so as a result of the disappearance of skilled middle-class employment caused by metropolitan changes brought on by globalization.

Data from Brookings (Ross and Bateman, 2019) were adopted for the path analysis because they include all low-wage workers, regardless of job type, thus making its database the most consistent with the other two income-based constructs of the polarized employment structure. Specifically, "low wage" is defined as the percentage of workers in an MSA whose income falls below a "low-wage threshold...of two-thirds median wages for full-time/full-year workers" (p. 6), where workers in the category rely on "their wages to cover basic living expenses" (p. 12).

In addition to the overall low-wage category, Brookings provides data broken down by age classifications, allowing the opportunity to identify more precisely those low-wage workers most characteristic of long-term exposure to conditions of a polarized employment structure. Since a third of low-wage workers are under age 30, and "less vulnerable" to a polarized employment structure by virtue of being "early in their careers" (p. 12), this age group was excluded. Specifically, low-wage percentage figures 
classified by an age bracket of 35 to 54 were selected as most representative of the lowwage worker because it focuses on "people in their prime working years [who] are more likely to work full time and raise a family" (p. 7), and "do not have a clear path to higher wages" (p. 12). This age-specific category is also comparable with the age profiles of the other two components of the polarized employment structure, both of which contain mostly mid-career workers or beyond, and a sparsity of young.

In contributing to the impact on economic inequality, low-wage workers appear to have a comparable significance to the other two employment-structure components. As such, low-wage workers exhibit strong influences on overall inequality (with Gini, $r=$ .53 , signif. @ .01) and with two out of the three disparity ratios (with the 90-10 ratio, $\mathrm{r}=$ .30 , signif. @ .05; with the 99-50 ratio, $r=.59$, signif @ .01). Its correlation with the 9520 ratio does not reach significance. In sum, the results are consistent with the construct assertion that as a causal influence, the greater the percentage of low-wage workers in the global-city workforce, the higher the state of economic inequality.

Composite effects on inequality. The path analysis in Figure 5 ends with a summary box containing pathway variables having direct correlations with Gini and the three disparity ratios. Within the box, they are separated into two categories of causal sources, based on whether they represent (1) a global city's cornerstone resources or (2) the global city's polarized employment structure. As the correlation box shows, the effects on inequality vary widely, indicating a very complex set of forces. Some pathway variables appear to have a more limited or nominal effect (e.g., sustainable development, unauthorized immigration), while others appear to be powerful across the board (e.g., innovation-resource agglomeration, hollowed middle class). Except for relationships that do not reach significance for one or more inequality indicators, the correlation 
outcomes are consistent with expectations as derived both from the composite and specific constructs of the global-city context. Nevertheless, a primary caveat concerning these results has to do with the potential for variables exogenous to the global-city setting to exert influence on one or more of pathway constructs or outcomes. Although beyond the scope of this research, knowing and accounting for such influences might plausibly alter relationships of one or more causal-path variables.

\section{Discussion}

National or extra-metropolitan origins of inequality aside, the emerging picture from the data appears to reinforce the construct plausibility that powerful circumstances exist within the global city which ultimately lead to very significant impacts on its overall economic inequality and specific inequitable income disparities. As just one example, the pathway leading from the global-city factor through the innovation-resources agglomeration illustrates what is also evident in inequality outcomes from the other global-city pathways (albeit to a lesser degree). In the agglomeration pathway, data show the global-city factor to be highly deterministic of the presence of this cornerstone resource $(r=.80)$, which in turn, has an influential direct effect on

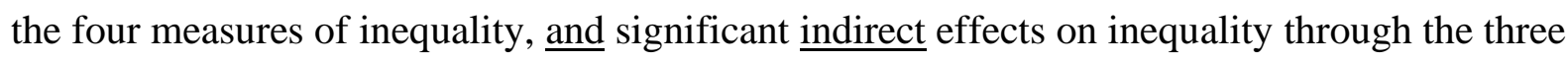
components of a polarized employment structure.

Regarding the indirect effects, and consistent with construct expectations, correlations show that a global-city's innovation agglomeration expresses a positive effect on the proportion of both UMC workers $(r=.67$, signif. @ .01) and low-wage workers $(r=.40$, signif. @ .01) in the employment structure, but an inverse (negative) effect on the proportion of middle-class workers $(r=-.64$, signif @ .01). In what may be a "triple whammy" effect these relationships identify a plausible cause for a polarized employment structure, where the global city's higher 
commitment to innovation agglomerations leads, on the one hand, to higher presences of UMC and low-wage workers, but concomitantly, to a "hollowing out" of middle-class workers.

In addition, a relevant secondary issue to polarization pertains to the presence of skewness in the employment structure. Specifically, while the UMC and low-wage workers share no significant relationship between each other, each has a significant inverse association with middle-class workers (for UMC/Middle Class, $r=-.29$, signif. @ .05; for Low-Wage Workers/Middle Class, $r=-.47$, signif. @ .01). But, the two correlations vary in magnitude, suggesting that hollowing of the middle induces a greater affinity for middle-class workers to migrate toward low-wage worker status than toward UMC status. What circumstances might account for this skewed outcome? Would such circumstances as racial or gender discrimination account for this variance or might middle-class worker motives and aspirations play a role in the skewed distribution? Perhaps some middle-class workers (or more likely their offspring) aspire toward upward mobility and UMC employment opportunities (in part by pursuing a college degree), but most instead have drifted downward to low-wage status? Beyond the cornerstoneresources effects, what else matters in explaining this skewed bi-polar employment structure?

A "triple whammy" effect on skewing and polarizing the employment structure also follows through without exception to shaping the inequality measures themselves. In contrast with other work (Hunt and Nunn, 2019), the correlation box in Figure 5 shows all three components of the polarized employment structure to contribute significantly to higher inequality outcomes. Hence, unlike other metropolitan areas less focused on economic development needs to maintain global advantage, global cities are more dependent on innovation agglomerations, which in turn, appear to create a polarized employment structure that leads to defining the conditions of economic inequality. 
Beside the path results presented here, there are likely other mediating variables, and perhaps more importantly, exogenous variables that have significant impacts on inequality by virtue of a causal connection with either the cornerstone resources or the polarized employment structure. However, because of the inordinate amount of complexity their introduction would add to the discussion, they were not included here for consideration. Nevertheless, they provide fertile ground for ongoing and future research.

Perhaps more immediately concerning are certain urban-based agents that are probably neither caused by nor the cause of inequality, but nevertheless compound the impacts of inequality, especially on the lives of those global-city households most vulnerable to economic hardship. One example of such agents is the considerably higher cost incurred to inhabit and participate in the high-energy global-city milieu driven by world competition. Among the many realities of a global city, the research makes clear that the comparatively larger mix of innovation-resource agglomerations, sustainable development ventures and unauthorized immigration combine to provide the necessary cornerstone resources to sustain those cities' connectivity and centrality to globalization.

However, maintaining such global leadership stature incurs additional cost burdens, less apparent in other metropolitan areas, that enlarge "barriers" to access and participation for some inhabitants. Such costs are not only considerably higher in global cities, but the ability to pay and rights of access vary disproportionally across income levels. Critical to understanding the context of economic inequality, two such costs in particular are strongly associated with an MSA's globally-competitive cornerstone resources, and include an elevated cost-of-living, and for many, the unaffordable cost of home-ownership/rental. Each is determined by metropolitan demand factors (such as prevailing lifestyles, employment mix, employee attributes, discretionary 
incomes, status consumption) and supply factors (such as exclusionary pricing, product substitutability and concentration of market power among shelter producers). In the case of home/shelter costs, urban development and land-use control (especially zoning requirements) are also in play to determine housing stock volume and character. In Figure 6, both of these costs are related to the global city's cornerstone resources for global advantage. For both cost categories, the correlations with the innovation agglomeration and the commitment of resources to sustainable development are uniformly strong. Even the draw of unauthorized immigration is significant although less so than the other two cornerstone resources.

\section{[FIGURE 6 ABOUT HERE]}

For both cost considerations in global cities, a dominant influence is employment mix, which, unlike other MSAs, is heavily skewed toward a technically-proficient workforce, and financially-connected, internationally-sophisticated corporate and not-for-profit operatives, most of whom enjoy high discretionary incomes. This is particularly evident in the type of employees drawn to the global city's agglomeration of innovation resources and globalization-focused institutions engaged in advanced producer services, multi-national research, and world entertainment venues. It is also apparent in the prevailing trust and optimism in technological solutions expressed by a global-city's comparably higher commitments to sustainable development.

However, the implicit lifestyles of such a workforce also raise specters for the cost of participation in the global-city's supercharged milieu. For those having the necessary high discretionary incomes required for access and proximity to participate, the elevated cost-of-living index and the cost of housing may be acceptable, even desirable. But, with the consequent "polarization of employment" (Autor, 2019), global cities leave many members of metropolitan 
employment categories without sufficient resources to live and sustain livelihoods in these areas, thus precluding them from participation, or limiting them by long inter-metropolitan commuting.

\section{Conclusion}

This research ends where it began with the urban dilemma over paradoxical paradigms the Three Es of economic development, ecological sustainability and socioeconomic equity. In a world of intense competitive globalization and saddled with insoluble tensions among the Three Es, urban policymakers are left to deal with the attendant wicked problems and difficult tradeoffs heightened by globalization and its manifestations in global cities. This research has purposely avoided making large policy statements about "what should be done", and it does not speculate on that front now. Instead, it has tried to empirically lay out some detailed circumstances found in global cities that might contribute to understanding the enormity of the issues involved in socioeconomic equity, especially income inequality. Hopefully, it may also set the stage for policy discussions.

In all of this, one takeaway seems clear: Quite apart from a nationwide origin of factors contributing to inequality, the evidence here suggests that globalization exhibits an equally significant but more "channeled" set of impacts on socioeconomic equity at a metropolitan scale. It does so specifically through the centrality of global cities acting as platforms in the playing out of world dynamics. In this way, urban outcomes driven by globalization often reflect intensification of paradoxical tradeoffs among the three Es involving zero-sum outcomes favoring economic development (and secondarily, sustainability) that cause exceptional inequalities to persist. Hence, although in conflict with some past work (e.g., Timberlake, et al, 2012; Strain, 2020), these results support those of others (e.g., Sassen, 1996; Zhong, Clark and Sassen, 2007; Florida, 2017; Bartik, 2019) in the notion that global cities matter in creating the 
"place-based" circumstances for socioeconomic inequality. In both the regressions and path analysis, an unmistakable pattern of impact on economic inequality is apparent that begins with the seven global-city attributes.

The intent of this effort was also to create a framework and analytical structure that may be useful to pursue areas not fully examined here and to incorporate unexplored aspects not addressed. For example, if the focus is moved from economic inequality to racial inequality, how do global-city pathway relationships inform the discussion? What other mediating variables come into play? In the case of racial inequality as an aspect of the COVID-19 crisis and simultaneous violent police actions against blacks, how might the circumstances laid out in the global-city path analysis inform and enlarge policy discussions on these subjects? In the area of personal health status, does the accentuated socioeconomic polarization in global cities matter to inhabitant wellbeing? For one, it matters in predicting heart-health outcomes (Mensah, 2020). For another, we know the incidence per hundred thousand inhabitants of COVID-19 cases is greater in global cities than in other MSAs (Centers for Disease Control and Prevention, 2020). Indeed, as both a cause and an outcome, socioeconomic inequality is at the root of the most significant policy issues of the day, including employment, education, health, and opportunity.

One should also ask about globalization's role and impact going forward in perpetuating socioeconomic equity in metropolitan areas. For instance, as global-city proponents devise ways that encourage more MSAs to become global (e.g., Clark, et al, 2020), are the results presented here reflecting a case of a "canary in the mineshaft"? Is the prevalence of exceptional inequality in global cities revealing what may be spreading across all metropolitan and rural areas as the demands of globalization become more ubiquitous beyond global cities? According to U.S. Census calculations (U.S. Census Bureau, 2012), over 80 percent of the nation's 330 million 
people reside in an urbanized setting defined as a core or multi-core (polycentric) metropolitan area, including surrounding suburbs. Of these 265 million urban inhabitants, only 29 percent (about 77 million) currently live in the 9 global cities identified in this study. Given such numbers, the association of inequality with globalization should be of significant concern going forward for Americans not currently located in a global city, especially regarding what it means to the socioeconomic status of those receiving less than the top $10 \%$ of household incomes.

Although national isolationism might seem like an attractive policy solution to globalization for some, the fruits produced by a contemporary U.S. economy are clearly fostered by and interdependent with multi-national firms, inventor networks, consumers and supplychains operating on a world scale. As some the managerial platforms of this world economic structure, American global cities cannot simply withdraw or reduce U.S. exposure to globalization. Instead of isolationism, policy development would be more fruitfully focused on programs that address globalization-induced inequalities at the metropolitan level.

Nevertheless, there is no panacea -- an urban-solutions approach is fraught with multiple complex issues, operating at different scales and consisting of individually unique circumstances. Moreover, "it involves not just trans-national actors in the global city, but also urban infrastructures and buildings containing offices, homes and entertainment facilities that are in play" (Sassen, 2020). Addressing such "wicked problems" will require metropolitan governance to function more effectively as an intergovernmental system (Boschken, 2017), dealing with individual circumstances along the pathways, and providing integrated outcomes that effectively achieve socioeconomic equity. Policy solutions successfully incorporating an equitable income distribution are unlikely to achieve a single comprehensive outcome, but rather are more likely to 
be incremental, multi-leveled and designed according to the individualized pathways influencing inequality.

\section{REFERENCES}

Abel, Jaison and Richard Deitz (2019), "Why are Some Places So Much More Unequal then Others?” Economic Policy Review, Vol. 25(1): 58-75.

Abrahamson, M. (2004), Global Cities (New York: Oxford University Press).

Acemoglu, Daron and Pascual Restrepo (2020), "Robots and Jobs: Evidence from US Labor Markets," Journal of Political Economy, Vol. 128(6): pp. 2188-2244.

Acemoglu, Daron and Pascual Restrepo (2019), “Automation and New Tasks: How Technology

Displaces and Reinstates Labor,” Journal of Economic Perspectives, Vol. 33(2): 3-30.

Alden, Edward (2016), Failure to Adjust (Lanham,MD: Rowan \& Littlefirld).

Adler, Patrick, Richard Florida, Karen King, and Charlotta Mellander (2018), "The City and High-Tech Startups: The Spatial Organization of Schumpeterian Entrepreneurship," Cities, Vol. 87: pp. 121-130.

Ananat, Elizabeth, Anna Gassman-Pines, Dania Francis and Christina Gibson-Davis (2017), “Linking Job Loss, Inequality, Mental health, and Education,” Science, Vol. 356(6343): 1127-1128.

Anderson, A. and J. Beckfield (2004), "Power and Position in the World City System," American Journal of Sociology, Vol. 109, pp. 811-851.

Atkinson, Robert, Mark Muro and Jacob Whiton (2019), "The Case for Growth Centers: How to Spread Tech Innovation Across America," (Wash. DC: Brookings Institution).

Autor, David (2019), "Work of the Past, Work of the Future,” (NBER Working Paper No 25588), Wash DC: National Bureau of Economic Research. 
Autor, D. H. and D. Dorn (2013). "The Growth of Low Skill Service Jobs and the Polarization of the US Labor Market,” American Economic Review, Vol. 103(5): pp. 1553-1597.

Autor, David, David Dorn, Lawrence Katz, Christina Patterson and John Van Reenen (2017), "Concentrating on the fall of the labor Share," American Economic Review: Papers \& Proceedings, Vol 107(5): 180-185.

Autor, David, Lawrence Katz and Melissa Kearney (2006), "Polarization of the U.S. Labor Market,” National Bureau of Economic Research, Working Paper No 11986, January.

Autor, David and Anna Solomons (2018), "Is Automation Labor-Replacing? Productivity Growth, Employment and the Labor Share,” Working paper 24871 (Wash, DC: National Bureau of Economic Research), February 27.

Badger, Emily (2017), "What Happens When the Richest U.S. Cities Turn to the World," New York Times, Business Section, p. 1, December 24.

Bartik, Timothy (2019), Making Sense of Incentives (Kalamazoo, MI: Upjohn Institute for Employment Research).

Beaverstock, J. V. (2004), “Managing Across Borders: Knowledge Management and Expatriation in Professional service Legal Firms," Journal of Economic Geography, Vol. 4(2), pp. 157-179.

Benner, Chris and Kung Feng (2020), “Elon Musk Reflects Silicon Valley’s 'Move Fast and Break Things' Culture," San Francisco Chronicle, May 15, online at: SFChronicle.com.

Berk, Richard (2004), Regression Analysis: A Constructive Critique (Thousand Oaks, CA: Sage Publications).

Berube, Alan (2018), “City and Metropolitan Income Inequality Data Reveal Ups and Downs through 2016," Brookings Report, February 5. 
Bischoff, Kendra and Sean Reardon (2013), "Residential Segregation by Income, 1970-2009," in John Logan (ed), The Lost decade? Social Change in the U.S. after 2000 (New York: Russell Sage Foundation).

Bonica, Adam, Nolan McCarty, Keith Poole and Howard Rosenthal (2013), "Why Hasn't Democracy Slowed Rising Inequality?”, Journal of Economic Perspectives, Vol. 27(3): pp. 103-124.

Boschken, Herman (1975), “The Logic of Protest Action,” Western Political Quarterly, Vol. 28(1): 59-71.

Boschken, Herman (1985), "Public Enterprise, Economic Development, and the Impact of Environmental Regulation: The Experience of American Seaports on the Pacific Rim," Review of Policy Research, Vol. 5(2): pp. 271-286.

Boschken, Herman (1988), Strategic Design and Organizational Change: Pacific Coast Seaports in Transition (Tuscaloosa: U. of Alabama Press).

Boschken, Herman (2002), Social Class, Politics and Urban Markets: The Makings of Bias in Policy Outcomes (Stanford, CA: Stanford University Press).

Boschken, Herman (2003), “Global Cities, Systemic Power, and Upper-Middle-Class Influence,” Urban Affairs Review, Vol. 38(6): 808-830.

Boschken, Herman (2008), “A Multiple-Perspectives Construct of the American Global City," Urban Studies, Vol. 45(1): 3-28.

Boschken, Herman (2013), "Global Cities are Coastal Cities Too: Paradox in Sustainability," Urban Studies, Vol. 50(9): 1760-1778. 
Boschken, Herman (2017), “Aligning a Multi-Government Network With Situational Context: Metropolitan Governance as an Organizational Systems Problem,” American Review of Public Administration, Vol. 47(2): pp 189-208.

Brint, Steven (2001), "Professionals and the 'Knowledge Economy': Rethinking the Theory of Postindustrial Society," Current Sociology, Vol. 49(4), pp 101-132.

Brose, Dominic (2014), Pathways to Urban Sustainability, National Research Council of the National Academy of Science (Wash. DC: National Academies Press).

Broto, Vanesa, Adriana Allen and Elizabeth Rapoport (2012), "Interdisciplinary Perspectives on Urban metabolism,” Journal of Industrial Ecology, Vol 16(6): 851-861.

Brundtland, Gro Harlem (1987), Our Common Future: The Report of the World commission on Environment and Development (New York: Oxford University Press).

Burns, Tom (2016), "Sustainable Development: Agents, Systems and the Environment,” Current Sociology Review, Vol. 64(6): 875-906.

Card, David (1998), “Falling Union Membership and Rising Wage Inequality,” NBER Working paper No. 6520, National Bureau of Economic Research.

Card, David and John DiNardo (2002), “Skill-Biased Technological Change and Rising Wage Inequality: Some Problems and Puzzles” Journal of Labor Economics, V. 20(4):733-783.

Card, David, Thomas Lemieux and Graig Riddell (2004), “Unions and Wage Inequality,” Journal of Labor Research, Vol. 25: 519-559.

Castells, M. (1996), The Rise of the Network City (Oxford: Blackwell).

Castells, M. (1989), The Informational City (Cambridge, MA: Basil Blackwell).

Centers for Disease Control and Prevention (2020), “Coronavirus Disease-2019: Cases in the U.S.," online at: https://www.cdc.gov/coronavirus/2019-ncov/cases-updates/cases-in-us.html 
Chetty, Raj, David Grusky, Max Hell, Nathaniel Hendren, Robert Manduca and Jimmy Narang (2016), "The Fading American Dream: Trends in Absolute Income Mobility Since 1940", NBER Working paper 22910, Cambridge MA: National Bureau of Economic Research.

Chetty, Raj, Nathaniel Hendren, Patrick Kline and Emmanuel Saez (2014), "Where is the Land of Opportunity? The Geography of Intergenerational Mobility in the United States," NBER Working Paper Series, No. 19843 (January).

Chiarenza, Gabriella (2018), “Introduction: What is Worker Voice?”, Amplifying Workers' Voices in an Evolving Economy, online: www.bostonfed.org/publications/invested.aspx. Clark, Greg and Tim Moonen (2013), The 10 Traits of Globally Fluent Metro Areas (Wash DC: Brookings Institution, Metropolitan Policy Program).

Clark, Greg, M. Gootman, M. Bouchet and T Moonen (2020), The Global Identity of Cities (Wash DC: Brookings Institution, Global Cities Initiative).

Clark, Terry (Ed.) (2004), The City as an Entertainment Machine (New York: JAI Press/Elsevier).

Clark, Terry and V. Hoffmann-Martinot (1998), The New Political Culture (Boulder, CO: Westview Press).

Clark, Terry and Dan Silver (2016), Scenescapes: How Qualities of Place Shape Social Life (Chicago: The University of Chicago Press).

Cui, X. (2018), "How Can Cities Support Sustainability: A Bibliographic Analysis of Urban metabolism," Ecological Indicators, Vol 93: 704-717.

Danielson, M. and J Doig (1982), New York: The Politics of Urban regional Development (Berkeley: U. of California Press). 
Derudder, Ben, P. Taylor, F. Wilcox and G. Catalano (2003), "Hierarchical Tendencies and Regional Patterns in the World City Network: a Global Urban Analysis of 234 Cities," Regional Studies, Vol. 37, pp. 875-886.

Derudder, Ben and F. Wilcox (2005), "An Appraisal of the Use of Airline Data in Assessments of the World City Network," Urban Studies, Vol. 42(13), pp. 2371-2388.

Duncan, Greg and Richard Murnane (2011), Whither Opportunity?: Rising Inequality, Schools and Children's Chances (New York: Russell Sage Foundation).

Emmenegger, Patrick, Silja Hausermann, Bruno Palier and martin Seeleib-Kaiser (2012), The Age of Dualization: The Changing Face of Inequality in Deindustrializing Societies (New York: Oxford University Press).

Emmons, William, Ana Kent and Lowell Ricketts (2018), “The Bigger They Are, The Harder They Fall: The Decline of the White Working Class," Essay No. 3, The Demographics of Wealth: 2018 Series (St Louis: Federal Reserve Bank), September.

Erie, Steven (2004), Globalizing L.A. (Stanford: Stanford University Press).

Farber, Henry, Daniel Herbst, Ilyana Kuziemko and Suresh Naidu (2018), "Unions and Inequality over the Twentieth Century: New Evidence from Survey Data," Working Paper 24587, National Bureau of Economic Research, May.

Federal Transit Administration (2017), "National Transit Database: Annual Metrics, 2017" (Wash, DC: U.S. Department of Transportation).

Florida, Richard (2012), The Rise of the Creative Class: And How It's Transforming Work, Leisure Community and Everyday Life - Revisited (New York: Basic Books).

Florida, Richard (2017), The New Urban Crisis (New York: Basic Books). 
Florida, Richard and Ian Hathaway (2018), "Rise of the Global Startup City," (New York: NYU Center for American Entrepreneurship), October.

Florida, Richard, Charlotta Mellander, and Karen King (2017), "Building 65 Million Good Jobs: The Geography of Low-Paid Service Class Jobs and How to Begin to Upgrade Them,” Martin Prosperity Institute, University of Toronto, September.

Forbes (2020), “The Richest in 2020: Mapping the World's Richest," on the internet at: https://www.forbes.com/billionaires/

Friedmann, J. (1986), “The World City Hypothesis,” Development and Change, Vol. 17, pp. 6983.

Friedmann, J. and G. Wolff (1982), "World City Formation: an Agenda for Research and Action,” International Journal of Urban and Regional Research, Vol. 6, pp. 309-344.

Giannone, Elise (2017), “Skill-Based Technical Change and Regional Convergence," online at: https://economicdynamics.org/meetpapers/2017/paper 190.pdf.

Gest, Justin (2016), The New Minority: White Working Class Politics in an Age of Immigration and Inequality (New York: Oxford University Press).

Gilens, Martin and Benjamin Page (2014), "Testing Theories of American Politics: Elites, Interest groups, and Average citizens," Perspectives on Politics, Vol. 12(3): 564-578.

Giuliano, Genevieve, Sanggyun Kang and Quan Yuan (2019), “Agglomeration Economies and Evolving Urban Form,” The Annals of Regional Science, Vol. 63: pp. 377-398.

Glaeser, Edward (2010), Agglomeration Economics (Chicago: U. of Chicago Press).

Glassman, Brian (2016), "Income Inequality Metrics and Economic Well-Being in U.S. Metropolitan Statistical Areas," a paper presented at the Western Economic Association Annual Meeting, Portland, OR, July. 
Glassman, Brian (2019), "Multidimensional Inequality: Measurement and Analysis Using the American Community Survey," paper presented at the Eastern Economic Association Annual Conference, February 28 - March 3, 2019.

Hacker, Jacob and Paul Pierson (2014), “After the 'Master Theory’: Downs, Schattschneider, and the Rebirth of Policy-Focused Analysis," Perspectives on Politics, Vol. 12(3): 643662.

Hall, Peter (1966), The World Cities (London: Heinemann).

Harrison, Ann (2017), “The Changing Landscape for International Trade: Protectionism, Bashing China, and the American Worker," a paper presented at the Jackson Hole Symposium, August 24-26.

Harrison, Ann (2018), "International Trade or Technology? Who is Left Behind and What to Do About it," Journal of Globalization and Development, Vol. 9(2), pp.1-15.

Hooker, Juliet and Alvin Tillery (2016), The Double Bind: The Politics of Racial \& Class Inequalities in the Americas (Washington DC: American Political Science Association).

Huggins, Robert and Hiro Izushi (2009), "Regional benchmarking in a Global Context:

Knowledge, Competitiveness, and Economic Development, Economic Development Quarterly, Vol. 23(4): pp 275-293.

Hulchanski, David (2010), The Three Cities Within Toronto: Income Polarization Among Toronto's Neighborhoods, 1970-2005 (Toronto: Cities Centre Press, University of Toronto).

Hunt, J., and Nunn, R. (2019). Is employment polarization informative about wage inequality and is employment really polarizing? IZA Discusson Papers, No. 12472. Available: https://www.econstor.eu/bitstream/10419/202818/1/dp12472.pdf. 
Hymer, S. (1971), “The Multinational Corporation and the Law of Uneven Development, in J.W. Bhagwati (Ed), Economics and World Order (New York: Macmillan), pp. 113-140. Inglehart, Ronald (2016), "Inequality and Modernization,” Foreign Affairs, Vol. 95(2): 2-10. Inglehart, Ronald and Paul Norris (2017), "Trump and the Populist Authoritarian Parties: The Silent Revolution in Reverse," Perspectives on Politics, Vol 15 (2): 443-454.

Jaimovich, Nir and Henry Siu (2018), “Job Polarization and Jobless Recoveries,” NBER Working Paper No. 18334, National Bureau of Economic Research, November.

Katz, Lawrence and Alan Krueger (2017), "Documenting Decline in U.S. Economic Mobility," Science, Vol. 356, Issue 6336, pp. 382-383.

Keeling, D.J. (1995), “Transport and the World City Paradigm” in P. Knox and P. Taylor (Eds), World Cities in a World System (New York: Cambridge University Press), pp. 115-131. Kerr, Clark (1963), The Use of the University (Cambridge, MA: Harvard University Press). Kochhar, Rakesh (2018), "The American Middle Class is Stable in Size, but Losing Ground Financially to Upper-Income Families," Facttank (Pew Research Center), September. Krugman, Paul (2018), “America’s Dismal Turning Point,” The New York Times, May 16. Lakner, C., M. Negre, J Cuesta and A. Silwa (2016), “Measuring Inequality Isn’t Easy or Straightforward,” World Bank Blog: : http://blogs.worldbank.org/developmenttalk/measuring-inequality-isn-t-easy-orstraightforward-here-s-why .

Lele, S. (1991), "Sustainable Development: A Critical Review,” World Development, Vol 19 (6): 607-621.

Lerman, R and S. Yitzhaki (1984), "A Note on the Calculation and Interpretation of the Gini Index,” Economics Letters, Vol. 18, pp. 363-368. 
Levy, Frank and Richard Murnane (1992), “U.S. Earnings Levels and Earnings Inequality: A Review of Recent trends and Proposed Explanations," Journal of Economic Literature, Nol 30: 1333-1381.

Lineberry, Robert and Edmund Fowler (1967), "Reformism and Public Policies in American Cities,” American Political Science Review, Vol. 61: 701-716.

Liu, Sifan and Joseph Parilla (2019), “How Startups Help Cities Measure Their Economic Development Frontier," Metropolitan Policy Program, Brookings Institution, October 24. Luxembourg Income Study (2019), Cross-National Data Center (Luxembourg: online at https://www.lisdatacenter.org/).

Manduca, Robert (2019), “The Contribution of National Income Equality to Regional Economic Divergence," Social Forces, Vol. 98(2): 622-648.

Marshall, J (2005), “Megacity, Mega Mess,” Nature, Vol. 475: 312-314.

Matsumoto, H. (2004), International Urban Systems and Air Passenger and Cargo Flows: Some Calculations," Journal of Air Transport Management, Vol. 10, pp. 241-249.

McKinsey Global Institute (2017), “Jobs Lost, Jobs Gained: Workforce Transitions in a Time of Automation," McKinsey \& Company, December.

Mian, Atif, Ludwig Straub and Amir Sufi (2020), "The Savings Glut of the Rich and the Rise in Household Debt," CESIFO Working Paper No 8201, Center for Economic Studies and ifo Institute, Munich, April.

Mishel, Lawrence and Jessica Schieder (2018), “CEO Compensation Surged in 2017,” Economic Policy Institute Report, August 16.

Monaghan, David and Peter Ikeler (2014), "Global Centrality and Income Inequality in U.S. Metropolitan Areas: A Test of Two Hypotheses,” Vol. 47, pp. 174-193. 
Moretti, Enrico (2013), “Real Wage Inequality,” American Economic Journal: Applied Economics, Vol. 5(1): 65-103

Moretti, Enrico (2019), “The Effect of High-Tech Clusters on the Productivity of Top Inventors," NBER Working Paper No. 26270 (Wash. DC: National Bureau of Economic Research), September.

Mosher, James (2007), “U.S. Wage Inequality, Technological Change, and Decline in Union Power," Politics \& Society, Vol. 35(2): 225-264.

Mounk, Yascha (2018), “America Is Not a Democracy,” The Atlantic, March, pp. 80-87.

Muro, Mark (2020), “No Matter Which Way You Look At It, Tech Jobs Are Still Concentrating In Just a Few Cities," online at: https://www.brookings.edu/research/tech-is-stillconcentrating/?preview id $=722376$.

Muro, Mark, J. Rothwell, S. Andes, K. Fikri and S Kulkarni (2015), “America’s Advanced Industries: What They Are, Where They Are, and Why They Are," (Wash, DC: The Brookings Institution), February.

Muro, Mark and Jacob Whiton (2019), “Who's Employed by the Lifestyles of the Rich and Famous?" (Wash DC: The Brookings Institution).

Muro, Mark and Jacob Whiton (2019a), "The Case for Growth Cities: How to Spread Tech Innovation Across America" (Wash DC: The Brookings Institution).

Muro, Mark, Robert Maxim and Jacob Whiton (2019), “Automation and Artificial Intelligence: How Machines are Affecting People and Places," (Wash. DC: The Brookings Institution), January.

Muro, Mark, Jacob Whiton and Robert Maxim (2019), "What jobs Are Affected by AI" (Wash DC: The Brookings Institution), November. 
Muro, Mark and Robert Atkinson (2020), “Countering America’s Regional Economic Disparities is Going to Take More Than Hope,” (Wash, DC: American Enterprise Institute), February.

Murray, Kate and David Marx (2013), “Attitudes Toward Unauthorized Immigrants, Authorized Imigrants and Refugees,” Cultural Diversity and Ethnic Minority Psychology, Vol. 19(3): pp. 332-341.

New York Times (2020), “Coronavirus in the U.S.: Latest Map and Case Count,” online at: https://www.nytimes.com/interactive/2020/us/coronavirus-us-cases.html

Nisbet, Robert (1966), The Sociological Tradition (New York: Basic Books).

Nyman, J. (1996), "Breaking the Rules: Miami in the Urban Hierarchy,” Urban Geography, Vol. 17, pp. 5-22.

Ostrom, Elinor (2009), “A General Framework for Analyzing Sustainability of Social-Ecological Systems," Science, Vol. 325: 419-422.

Packard, Vance (19 ), The Status Seekers (New York: Pocket Books).

Parkin, S., F Sommer and S. Uren (2003), "Sustainable Development: Understanding the Concept and Practical Challenge," Engineering Sustainability 156, Proceedings of the Institution of Civil Engineers, Vol. ES1: pp 19-26, March.

Perkins, S.J. (1997), Internationalization: The People Business (London: Kogan Page).

Pew Research Center (2015), “The American Middle Class is Losing Ground,” December 9 (www.pewresearch.org). 
Pew Research Center (2018), "Distribution of Adults by Income Tier in U.S. Metropolitan Areas, 2016," an Excel Spreadsheet downloaded at: https://www.pewresearch.org/fact$\underline{\operatorname{tank} / 2018 / 09 / 06 / \text { the-american-middle-class-is-stable-in-size-but-losing-ground- }}$ financially-to-upper-income-families/.

Pierson, Paul (2016), The Double Blind: The Politics of Race and Class Inequality in the Americas (Washington DC: American Political Science Association).

Piketty, Thomas, (2014), Capital in the $21^{\text {st }}$ Century (Cambridge: Harvard University Press). Piketty, Thomas, Emmanuel Saez and Gabriel Zucman (2016), "Distributional National Accounts: Methods and Estimates for the United States," NBER Working Paper Series, No. 22945 (December).

Pilka, Martin and Nikolay Sluka (2019), "US Global Cities as Centres of Attraction of Foreign TNCs" Bulletin of Geography: Socio-Economic Series, Vol. 46(46), pp. 137-147.

Porter, Michael (1996), “Competitive Advantage, Agglomeration Economies, and Regional Policy,” International Regional Science Review, Vol. 19(1): pp. 85-94.

Porter, Michael (1998), “Clusters and the New Economics of Competition,” Harvard Business Review, Vol. Nov/Dec, pp. 77-90.

Rath, J. (2002), "Immigrants and the Tourist Industry: The Commodification of Cultural Resources," a paper presented at the $15^{\text {th }}$ World Congress of Sociology, Brisbane, Australia, July.

Reeves, Richard (2018), Dream Hoarders (Wash DC: Brookings Institution Press.

Reich, Robert (1992), The Work of Nations, Preparing Ourselves for $21^{\text {st }}$ Century Capitalism (New York: Vintage). 
Ribeiro, David, et al (2019), “The 2019 City Clean Energy Scorecard,” (Wash. DC: The American Council for an Energy-Efficient Economy), July.

Rittel, H W J and M. Webber (1973) 'Dilemmas in a General Theory of Planning', Policy Sciences, 4(2): pp 155-169.

Ross, Martha and Nicole Bateman (2019), "Meet the Low-Wage Workforce,” Metropolitan Policy Program, Brookings Institution, November.

Rothman, Joshua (2020), “The Equality Conundrum,” The New Yorker, January 6.

Rothwell, Jonathan (1019), A Republic of Equals: A Manifesto for a Just Society (Princeton: Princeton University Press).

Saez, Emmanuel (2015), "Striking it Richer, The Evolution of Top Incomes in the U.S.," unpublished manuscript, University of California, Berkeley, June 25.

Saez, Emmanuel and Gabriel Zucman (2014), Wealth and Inequality in the United States since 1913: Evidence from Capitalized Income Tax Data,” NBER Working Paper Series, No. 20625 (October).

Saha, Devashree and Robert Paterson (2008), "Local Government Efforts to Promote the 'Three Es' of Sustainable Development," Journal of Planning Education and Research, Vol. 28: 21-37.

Sassen, Saskia (1996), "Service Employment Regimes and the New Inequality,” in Enzo Mingione, Urban Poverty and the Underclass: A Reader (Oxford, UK: Blackwell). Sassen, Saskia (2001), The Global City (Princeton, NJ: Princeton University Press). 
Sassen, Saskia (2004), “The Repositioning of Citizenship: Toward New Types of Subjects and Spaces of Politics," a paper presented at the Conference on Transforming Citizenship, Transnational Membership, Participation and Governance, Campbell Public Policy Institute, Maxwell School of Syracuse University, April.

Sassen, Saskia (2020), an email correspondence with Herman Boschken, July 13.

Saxenian, A. (1996), Regional Advantage (Cambridge: Harvard University Press).

Scheidel, Walter (2017), The Great Leveler: Violence and the History of Inequality, (Princeton: Princeton University Press).

Silver, Daniel, Zack Taylor and Fernando Calderon-Figueroa (2019), "Populism in the City: The Case of Ford Nation," International Journal of Politics, Culture, and Society, published online, January 3.

Sommeiller, E and M Price (2018), The New Gilded Age (Washington, DC: Economic Policy Institute).

Starmans, Christina, Mark Sehskin and Paul Bloom (2017), "Why People Prefer Unequal Societies," Nature Human Behavior, Vol. 1:1-7.

Stiglitz, Joseph (2016). "Inequality and Economic Growth,” The Political Quarterly, Vol. 86 (51): $135-155$.

Storme, T, B Derudder and S Dorry (2019), "Introducing Cluster Heatmaps to Explore City/Firm Interactions in World Cities," Computers, Environment and urban Systems, Vol. 76, pp. $57-68$.

Strain, Michael (2020), "The American Dream is Alive and Well: We have Bigger Issues than Inequality," New York Times, Opinion Section, May 18. 
Sunstein, Cass (1999), “The Law of Group polarization,” Olin Law \& Economics Working Paper No. 91 (Chicago: The Law School, University of Chicago).

Tajbakhsh, K. (2001), The Promise of the City: Space, Identity and Politics in Contemporary Thought (Berkeley: U. of California Press).

Taylor, P.J. and R.E. Lang (2005), “U.S. Cities in the 'World City Network,” Survey Series, Metropolitan Policy Program (Wash DC: Brookings Institution), February,

Thal, Adam (2020), "The Desire for Social Status and Economic Conservatism Among Affluent Americans," American Political Science Review, Vol. 114(2): pp. 426-442.

Timberlake, Michael, Matthew Sanderson, Xuilian Ma, Ben Derudder, Jessica Winitzky and Frank Witlox (2012), “Testing a Global City Hypothesis: An Assessment of Polarization across US Cities," City \& Community, Vol. 11(1): pp. 74-93.

Times Higher Education (2019), “World University Rankings 2019,” found online at: https://www.timeshighereducation.com/world-university-rankings/2019/worldranking\#!/page/0/length/25/sort by/rank/sort order/asc/cols/stats

Turner, R, S Subak, and W Adger (1996), "Pressures, Trends and Impacts in the Coastal Zone:Interactions between Socio-economic and Natural Systems," Environmental Management, Vol 20: 159-173.

U.S. Census Bureau (2012), "How Do We Measure Urban Areas," found online at: https://www.census.gov/newsroom/blogs/random-samplings/2012/04/how-do-we-measureurban-areas.html

U.S. Bureau of Labor Statistics (2015), "Measuring Wage Inequality Within and Across U.S. Metropolitan Areas, 2003-13," Monthly Labor Review, September.

U.S. Bureau of Labor Statistics (2017), "Manufacturing (NAICS 32-33) Workforce Statistics." U.S. Census Bureau (2017), "FT920 U.S. Merchandise Trade: Selected Highlights” U.S. Department of Commerce, December. 
U.S. Census Bureau (2018), “Gini Index of Income Inequality - 5-Year Estimates,” 2013-2017 American Community Survey.

U.S. Census Bureau (2018b), "Selected Economic Characteristics,” (Nos S1501 and DP03) 5Year Estimates, 2013-2017 American Community Survey.

U.S. Census Bureau (2018c), "Income in Past 12 Months," Table S1901, American Community Survey.

U.S. Census Bureau (2019), “Gini Index," found online at: https://www.census.gov/topics/incomepoverty/income-inequality/about/metrics/gini-index.html .

U.S. Census Bureau (2019), “U.S. and World Population Clock,” found online at: https://www.census.gov/popclock/

U. S. Department of Transportation (2017), “Annual Airport International Passengers Inbound + Outbound," International Aviation Developments Series.

U.S. Patent \& Trademark Office (2019), "Patenting In Technology Classes, Breakout by Origin, U.S Metropolitan and Micropolitan Areas, 2000-2015,” found online at: https://www.uspto.gov/web/offices/ac/ido/oeip/taf/cls cbsa/allcbsa gd.htm

Veblen, Thorstein (1899), The Theory of the Leisure Class (New York: Viking Press).

Webb, Michael (2020), “The Impact of Artificial Intelligence on the Labor Market,” unpublished paper, online at: https://web.stanford.edu/ mww/webb_jmp.pdf

Weininger, Elliot, Annette Lareau and Dalton Conley (2015), “What Money Doesn’t Buy: Class Resources and Children's Participation in Organized Extracurricular Activities," Social Forces, Vol 94(2): 479-503.

Wilson, James and Edward Banfield (1964), "Public-Regardingness as a Value Premise in Voting Behavior,” American Political Science Review, Vol. 58(4): pp. 876-887. 
Wilson, William J. (1997), “When Work Disappears,” Political Science Quarterly, Vol. 111(4): pp. 567-575.

Wolman, Abel (1965), “The metabolism of Cities,” Scientific American, Vol. 213(3):178-193.

Zhong, Xing, Terry Nichols Clark and Saskia Sassen (2007), "Globalization, Producer Services and Income Inequality across US Metro Areas,” International Journal of Sociology, Vol.17(3): pp. 385-391. 
Figure 1: Global City Factor Correlations with Dimension variables, 53 U.S. MSAs

Dimension Variables

Factor Correlation

1. Spatial/Form of Urban Place $.976 * *$

2. Global Command \& Control Platform .951**

3. World Research Crucible $.886^{* * *}$

4. Global Entertainment Machine $.967 * *$

5. Global Multicultural Center $.975 * *$

6. International Transport Gateway $.921 * *$

7. Rail Transit Mobility Infrastructure $.928 * *$

** Correlation significant at 0.01 level or greater (two-tailed). 


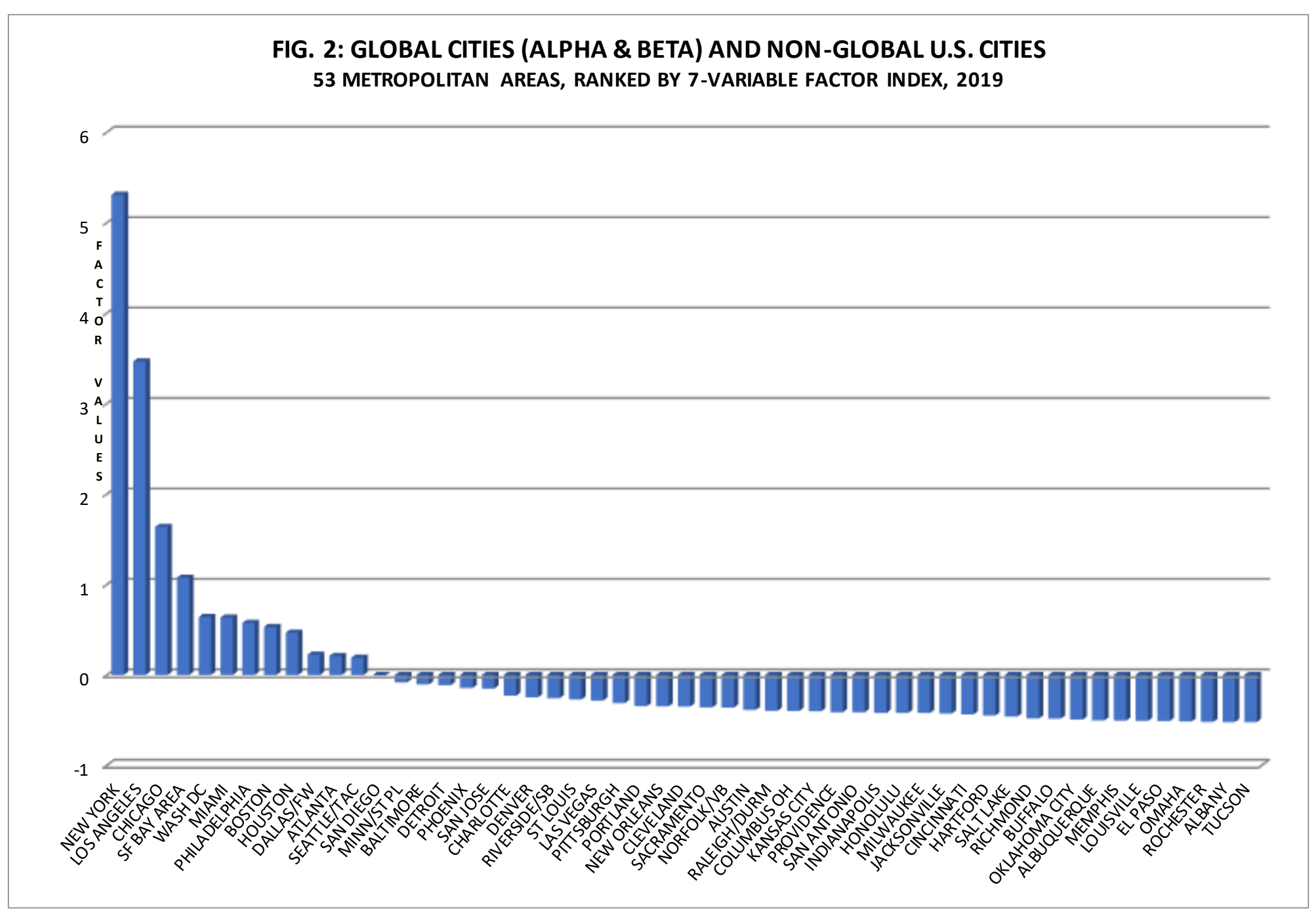


Figure 3a: Global City Factor Correlations with Inequality Indicators, 53 U.S. MSAs

Inequality Measures

Global-City Factor

Gini Index $.56 * *$

Income Disparity - 90-10 Ratio

$.52 * *$

Income Disparity - 95-20 Ratio

$.39 * *$

Income Disparity - 99-50 Ratio

$.55^{* *}$

** Correlation significant at the .01 level

or greater (two-tailed)

FIG. 3b: SCATTERPLOT - GINI INDEX FOR 53 MSAs BY GLOBAL CITIES 7-DIMENSIONS FACTOR

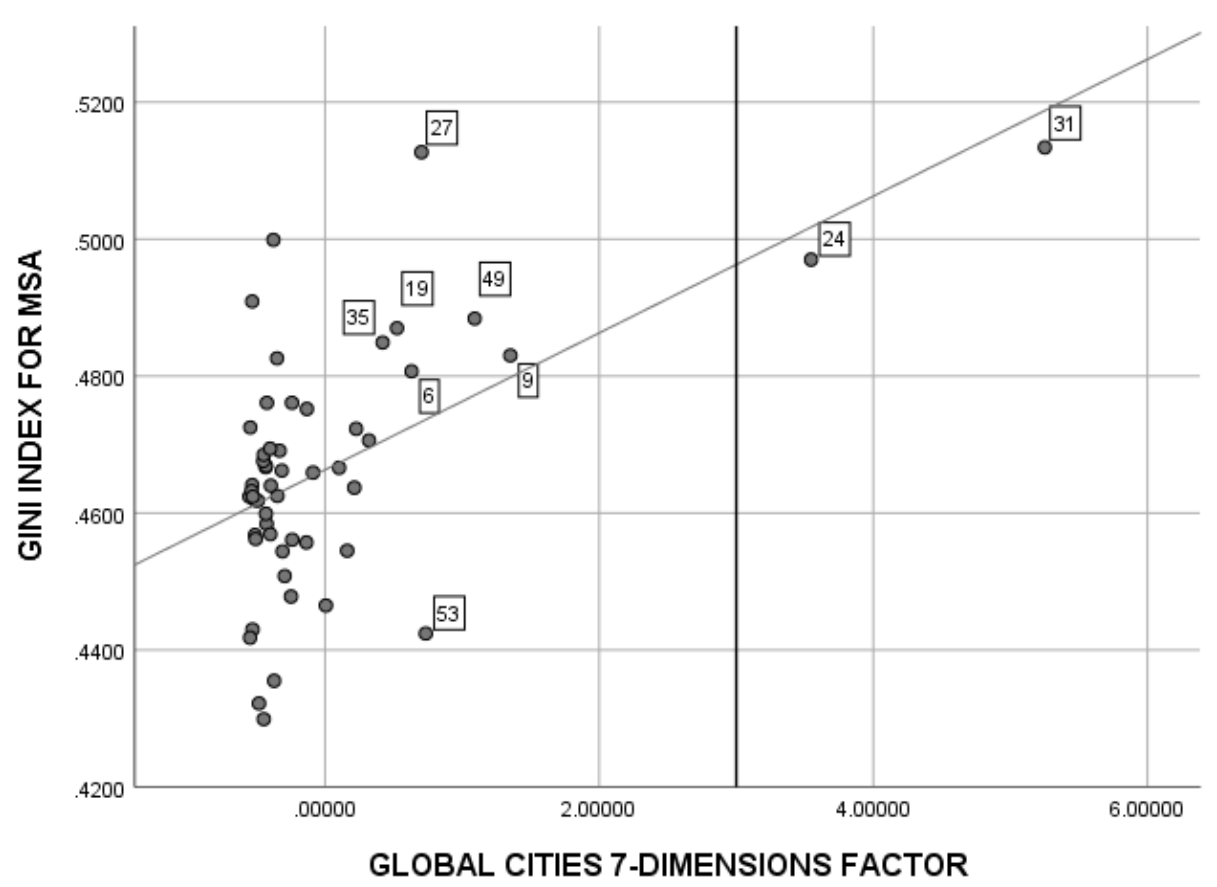

NINE GLOBAL CITIES: $\mathrm{NY}=31, \mathrm{LA}=24, \mathrm{CHI}=9, \mathrm{SF}=49, \mathrm{WDC}=53, \mathrm{MIA}=27, \mathrm{BOS}=6, \mathrm{HOU}=19, \mathrm{PHL}=35$ 
Figure 4: Multiple Regression - Global Cities Factor and Rival Hypotheses, 53 U.S. MSAs

\begin{tabular}{|c|c|c|c|c|c|c|c|c|c|c|c|c|}
\hline \multirow{3}{*}{$\begin{array}{l}\text { Independent } \\
\text { Variable }\end{array}$} & \multicolumn{6}{|c|}{ De pe $n d e n t$} & \multicolumn{3}{|c|}{ V ariable } & & & \\
\hline & \multicolumn{3}{|c|}{ Gini Index } & \multicolumn{3}{|c|}{ 95-20 Ratio } & \multicolumn{3}{|c|}{ 90-10 Ratio } & \multicolumn{3}{|c|}{ 99-50 Ratio } \\
\hline & Beta & $\mathrm{t}$ & Signif. & Beta & $\mathrm{t}$ & Signif. & Beta & $\mathrm{t} S$ & Signif. & Beta & $\mathrm{t}$ & Signif. \\
\hline 1. Global-Cities Factor & .623 & 5.53 & .000 & .377 & 2.80 & .007 & .585 & 4.86 & .000 & .624 & 5.42 & .000 \\
\hline 2. \% Manufacture Employ & .137 & 1.23 & .226 & -.051 & -0.38 & .706 & .101 & 0.85 & .403 & .123 & 1.08 & .286 \\
\hline 3. Mfg Productivity/Tech & .195 & 1.71 & .093 & .120 & 0.88 & .382 & -.075 & -0.61 & .543 & -.079 & -0.68 & .499 \\
\hline 4. \% Unionized Employ & -.197 & -1.70 & .096 & .087 & 0.62 & .536 & -.106 & -0.86 & 5.397 & -.258 & -2.17 & .035 \\
\hline Model Summary: & $\begin{array}{l}\mathrm{R} \mathrm{Sq} \\
.420\end{array}$ & $\begin{array}{c}F \\
8.7\end{array}$ & $\begin{array}{l}\text { Signif. } \\
.000\end{array}$ & $\begin{array}{l}\mathrm{R} \mathrm{Sc} \\
.169\end{array}$ & $\begin{array}{lr}q & F \\
7 & 2.4\end{array}$ & $\begin{array}{l}\text { Signif. } \\
.059\end{array}$ & $\begin{array}{r}\mathrm{R} \mathrm{Sq} \\
.336\end{array}$ & $\begin{array}{c}F \\
6.1\end{array}$ & $\begin{array}{l}\text { Signif. } \\
.000\end{array}$ & $\begin{array}{l}\mathrm{R} \mathrm{Sq} \\
.374\end{array}$ & $\begin{array}{c}F \\
7.8\end{array}$ & $\begin{array}{c}\text { Signif. } \\
.000\end{array}$ \\
\hline
\end{tabular}




\section{FIGURE 5: PATH ANALYSIS}

\section{CORNERSTONE RESOURCES} FOR GLOBAL ADVANTAGE
POLARIZED EMPLOYMENT \& SOCIAL STRUCTURE
INCOME INEQUALITY

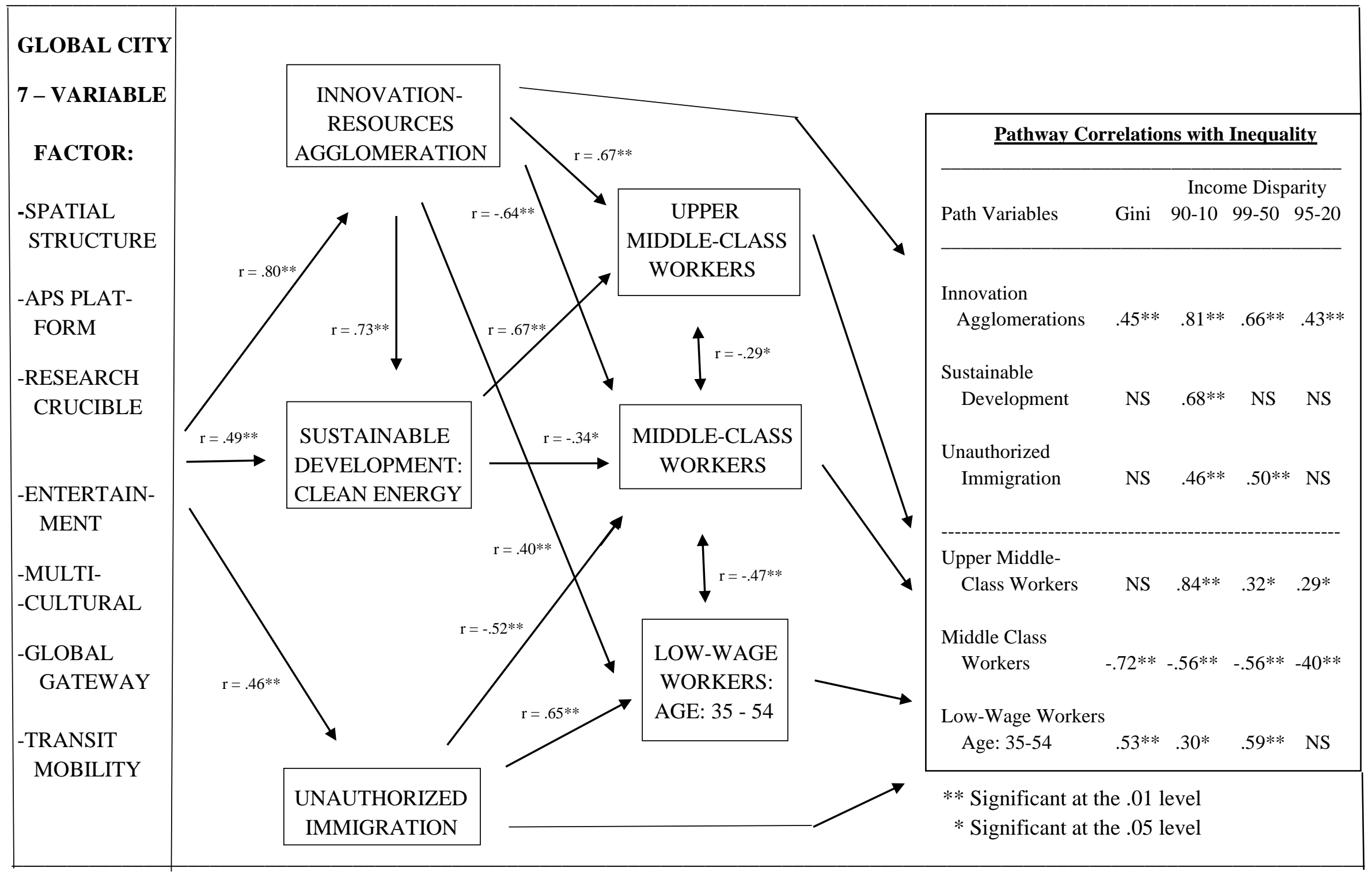


Figure 6: Access Cost Correlations with Global-City Cornerstone Resources

\begin{tabular}{lcc}
\hline $\begin{array}{l}\text { Cornerstone } \\
\text { Resources: }\end{array}$ & $\begin{array}{c}\text { Cost of } \\
\text { Living }\end{array}$ & $\begin{array}{c}\text { Cost of } \\
\text { Home }\end{array}$ \\
\hline $\begin{array}{l}\text { 1. Innovation- } \\
\text { Resources } \\
\text { Agglomeration }\end{array}$ & .78 & .69 \\
$\begin{array}{l}\text { 2. Sustainable } \\
\text { Development }\end{array}$ & .75 & .58 \\
$\begin{array}{l}\text { 3. Unauthorized } \\
\text { Immigration }\end{array}$ & .44 & .44
\end{tabular}

All Significant at the .01 level 